\title{
The impact of diameter, number of ribs, percentage of steel, compressive strength and cover thickness on the large concrete dome
}

\author{
Dr. Hani Aziz Ameen \\ Asst. Prof., Pumps Engineering Department - Technical College / Al-Musaib - Iraq \\ E-mail:haniazizameen@yahoo.com
}

\begin{abstract}
This paper presents an investigation of the finite element analysis via ANSYS12 software for the large concrete dome. Very few studies have been devoted to the case of the analysis of large concrete dome. The prediction of the analysis of large diameter concrete dome is a challenging task. This paper have a novel discussion for the non linear analysis of reinforced concrete or composite hemispherical dome of monolithically or partially interconnected ribs, running in the meridional of the dome. A simplified three dimensional finite element model is developed in ANSYS12, this analysis, which may be applied to three cases of hemispherical dome: unribbed, monolithic ribs, and composite ones. The interfaces between the precast radial ribs and the abutting cover in composite dome is modeled. Material non-linearity due to the cracking and crashing of the concrete and yielding of the reinforcing steel bars are taken into consideration during the analysis. The current application included initially, the analysis of unribbed hemispherical reinforce concrete dome by the recent finite element model and by the membrane theory of shells, have shown very high agreement in the membrane meridional and hoop normal stresses values which were all within the 3.3\% margin of difference. Application of the present numerical model to hemispherical ribbed dome of the two specified types (monolithic concrete and composite ones) has produced variations of the three orthogonal normal stresses and the vertical displacement along meridional path from apex to base of dome, which are in perfect agreement with the logical structure behavior of such dome that is drawn by high structural inspection. A wide parametric study the impact of diameter, number of ribs, percentage of Steel, compressive strength and cover thickness on the large dome for the three cases to evaluate the quantities affect of the main parametric in the aspects of geometry, constitutions and material properties. Numerical percentages of the variation of ultimate loads and vertical deflection at dome apex with variation of each of those parametric has been computed when given the fundamental guidelines for the structural design of such dome.
\end{abstract}

Keywords: finite element method, concrete, spherical shell, ANSYS, dome

\section{INTRODUCTION}

In the recent years, thin shell structures find wide applications in many branches of technology such as space vehicle, nuclear reactor, pressure vessels, roofs of industrial building and auditoriums (Chandrashekhra,1995 and Tony,1996). From the point of view of architecture, the development of shell structure offers unexpected possibilities and opportunities for the combined realization of functional, economic and aesthetic aspects (Chandrashekhra,1995). Chen,1979, studied and tested conical concrete-shell specimens with widely varying material properties and traced their loaddeformation response, internal stresses and crack propagation through the elastic, inelastic, and ultimate stress ranges. Zweilfel,1997, presented a small diameter concrete dome with alternate forming system, he built a dome of $16 \mathrm{ft}$ in diameter and $8 \mathrm{ft}$ in height. Manasrah, 1993, investigated the effectiveness of connection elements of the segmental cylindrical shell units subjected to knifeedge load at the crown of the shell. A total of eight full scale shell unit models with four types of connections were constructed and tested. All the models were of $450 \mathrm{~mm}$ width, $35 \mathrm{~mm}$ thickness, $1000 \mathrm{~mm}$ head of the crown and $4000 \mathrm{~mm}$ covered span. Ford,2001, studied the stress-strain and fracture behavior for both reinforced and unreinforced concrete is tailored to range from strong linear elastic but brittle to tough and ductile by various combinations of rubbery methyle methacrylate. Such composite specimens are found ideal for the purpose of comparison with various material models now available in the 
extended NONSAP program. Jackson, 2002, reported the finding of a structural evaluation of the 5 meter diameter observatory dome structure constructed by Observa-Dome laboratories, Inc. Regarding to the presentation of literature review, it should be emphasized that no investigation related to the analysis of large concrete thin shell dome is found. So it can be represented this work as a first one in the field of the study of concrete dome. The main objectives of this study are conducting an analytical study on the behavior of reinforced concrete ribbed dome with precast rib and cast-inplace cover and concrete slab under monotonically increasing loads by using three dimensional finite element method of analysis with inclusion of material nonlinearities due to cracking of concrete, crushing of concrete, yielding of steel bars, nonlinearity of the stress-strain response of concrete and steel, and the interface changing status in analysis, modeling of the interface used to simulate the interface by taking into account both of the shear-friction mechanism (between precast reinforced concrete rib and cast-inplace cover) and the dowel action mechanism (of the reinforcing bars that are crossing the interface, which

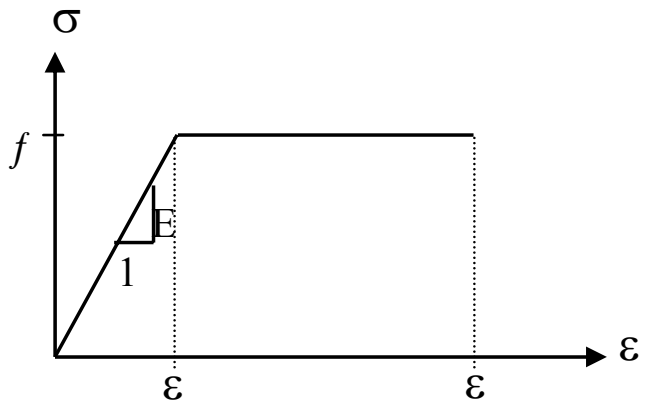

contribute to the overall shear stiffness of the joint) and the study of the load-deflection behavior of such cases as well as the maximum attained loads (load carrying capacity). The computer program ANSYS12 has also been used to study the effects of some material parameters used in the finite element model which deal with the composite construction. Checking and assessing the validity and accuracy of the adopted finite element modeling with available experimental test results are made.

Concrete Models Adopted in the Present Study: In the current study, concrete material models that deal with the nonlinear three dimensional analysis of reinforced concrete members under static increasing load are considered. These models treat the concrete as being a linear elastic-perfectly plastic-brittlefracture material as shown in Fig.(1). The concrete under a triaxial stress state is assumed to crush or crack completely once the fracture surface is reached. The complete stress-strain relationship for a perfectly plastic-brittle fracture model is developed in three parts (Chatterjee,1998): (1) Before yielding, (2) During plastic flow, (3) After fracture.

Fig. (1) Uniaxial stress-strain relationship used for concrete.

This stress-strain relationship is expressed by a single value of Young's modulus, E, and a constant poisson's ratio, $U$. So this relation can be written in matrix form as:

$\{\sigma\}=\left[\mathrm{D}_{\mathrm{c}}\right]\{\varepsilon\}$

The matrix $\left[D_{c}\right]$ for uncracked elastic concrete can be defined by (Chatterjee,1998): 


$$
\left[D_{c}\right]=\frac{E}{(1+v)(1-2 v)}\left[\begin{array}{cccccc}
(1-v) & v & v & 0 & 0 & 0 \\
v & (1-v) & v & 0 & 0 & 0 \\
v & v & (1-v) & 0 & 0 & 0 \\
0 & 0 & 0 & \frac{(1-2 v)}{2} & 0 & 0 \\
0 & 0 & 0 & 0 & \frac{(1-2 v)}{2} & 0 \\
0 & 0 & 0 & 0 & 0 & \frac{(1-2 v)}{2}
\end{array}\right]
$$

The equivalent uniaxial stress-strains in the various stages are given by:
1) For $\quad \sigma \leq f^{\prime}{ }_{c}$
then $\quad \sigma=\mathrm{E}_{\varepsilon}$
2) For $\quad \varepsilon \geq \frac{\mathrm{f}_{\mathrm{c}}^{\prime}}{\mathrm{E}}$
then $\quad \sigma=f^{\prime}{ }_{c}$

The incremental stress-strain relationship can be expressed as:

$$
\{\mathrm{d} \sigma\}=\left[\mathrm{D}_{\mathrm{c}}\right]\{\mathrm{d} \varepsilon\}
$$

Determination of the Model Parameters: A total of five strength parameters are needed to define the failure surface as well as an ambient hydrostatic

stress state $\left(f_{c}^{\prime}, f_{t}, f_{c b}, f_{1}, f_{2}\right.$ and $\left.\sigma_{h}^{a}\right)$, these are shown in Fig.(2).

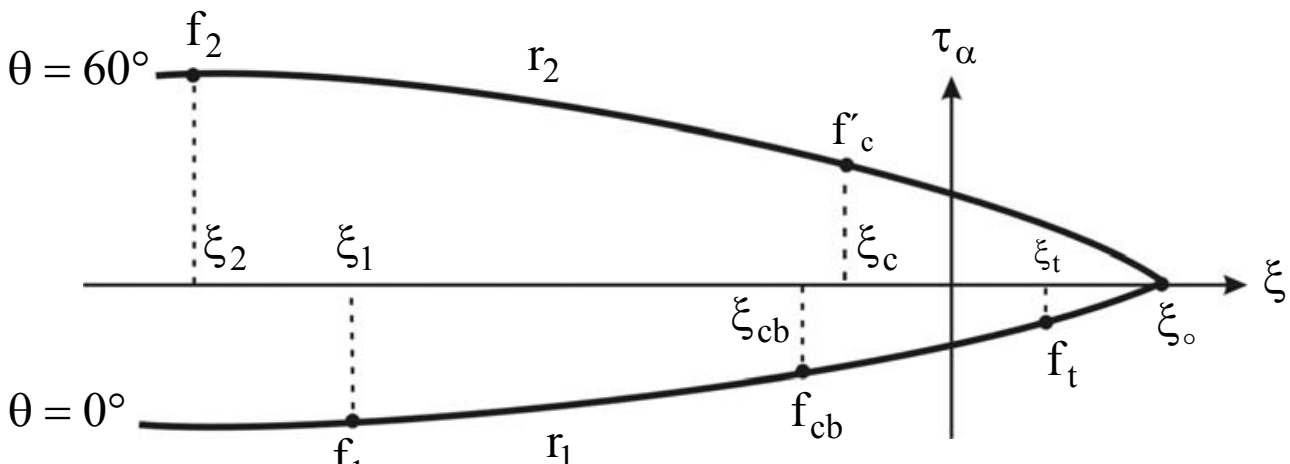

Fig.2 A profile of the failure surface as a function of five parameters

$f_{c}^{\prime}$ and $f_{t}$ can be specified from two simple tests. The other three constants can be determined from :

$$
\begin{aligned}
& f_{c b}=1.2 f_{c}^{\prime} \\
& f_{1}=1.45 f_{c}^{\prime} . \\
& f_{2}=1.725 f_{c}^{\prime}
\end{aligned}
$$

However, these values are valid only for stress states where the following condition is satisfied

$$
\left|\sigma_{h}\right| \leq \sqrt{3} \mathrm{f}_{\mathrm{c}}^{\prime}
$$

where:

$$
\sigma_{\mathrm{h}}=\frac{1}{3}\left(\sigma_{\mathrm{xp}}+\sigma_{\mathrm{yp}}+\sigma_{\mathrm{zp}}\right)
$$

Condition(7) applies to stress situations with a low hydrostatic stress component. In Fig.(2), the lower curve represents all stress states such that $\left(\theta=0^{\circ}\right)$, while the upper curve represents stress states for $\left(\theta=60^{\circ}\right)$. Here $\theta$ is defined as the angle of symmetry. The axis $(\xi)$ represents the hydrostatic length. The materials properties of our research is taken as in table(1). 
Table 1. Material properties used for reinforcing concerted ribbed dome Concrete

\begin{tabular}{|c|l|c|}
\hline $\mathrm{E}_{\mathrm{c}}{ }^{*}$ & Young's modulus (MPa) & 25800 \\
\hline$f^{\prime} \mathrm{C}$ & Compressive strength (MPa ) & 30.36 \\
\hline$f_{t}^{* *}$ & Tensile strength (MPa ) & 3.1 \\
\hline$U^{* * *}$ & Poissons ratio & 200000 \\
\hline Reinforcing steel & Young s modulus (MPa ) & 344.8 \\
\hline $\mathrm{E}_{\mathrm{s}}^{* * *}$ & Yield stress (MPa ) & 0.3 \\
\hline$f_{y}$ & Poisson's ratio & \\
\hline$U^{* * *}$ & & 2000 \\
\hline
\end{tabular}

Interface properties

\begin{tabular}{|l|l|c|}
\hline$K_{n}$ & Normal stiffness $(\mathrm{kN} / \mathrm{m})$ & 1638.3 \\
\hline $\mathrm{K}_{\mathrm{s}}$ & Tangential shear stiffness $(\mathrm{kN} / \mathrm{m})$ & $1638.3 \times 10^{-2}$ \\
\hline$\mu$ & Coefficient of friction & 1 \\
\hline$\alpha_{1}^{* * *}$ & \multirow{2}{*}{ Tension stiffening parameters } & 60 \\
\hline$\alpha_{2}^{* * *}$ & & 0.6 \\
\hline$\beta_{0}^{* * *}$ & \multirow{2}{*}{ Shear transfer parameters } & 0.3 \\
\hline$\beta_{\mathrm{c}}^{* * *}$ & & 0.7 \\
\hline
\end{tabular}

$\left.{ }^{*}\right) \mathrm{E}_{\mathrm{c}}=4700 \sqrt{f_{c}^{\prime}}$

Finite Element Model of Concrete: In the current study, three dimensional 8-node solid elements (Solid65) are used to model the concrete (ANSYS12 manuals help,2009). The element has eight corner nodes, and each node has three degrees of freedom $\mathrm{u}, \mathrm{v}$ and $\mathrm{w}$ in the $\mathrm{x}, \mathrm{y}$ and $\mathrm{z}$ directions respectively.

Reinforcement Idealization: In developing a finite element model for reinforced concrete members the author suggested three alternative representations of reinforcement can usually be used, these are given as follows:

Distributed Representation: In this approach, the reinforcement is assumed to be distributed in $\left.{ }^{(* *}\right)$ Assumed value

a layer over the element in any specified direction. To construct the constitutive relation of a composite concrete-reinforcement, perfect bond is assumed (Fig.(3.a)).

Discrete Representation:One dimensional bar element may be used in this approach to simulate the reinforcement. Discrete representation has been widely used due to its versatility and capability to adequately account for the bond-slip and dowel action phenomena (Fig.(3.b)). 
Am. J. Sci. Ind. Res., 2010, 1(3): 472-495

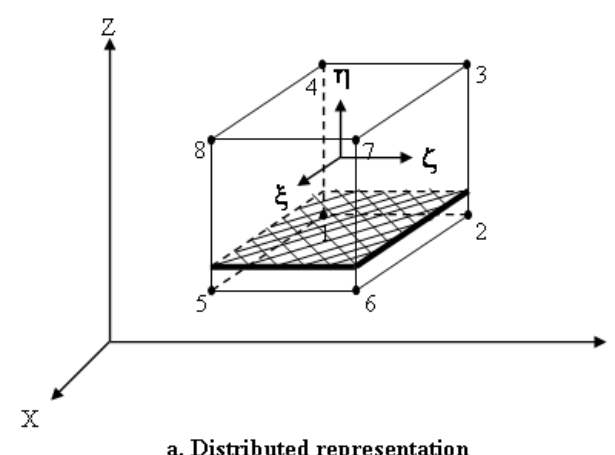

a. Distributed representation

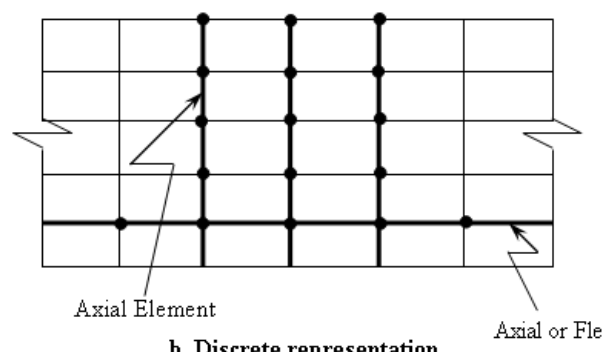

b. Discrete representation

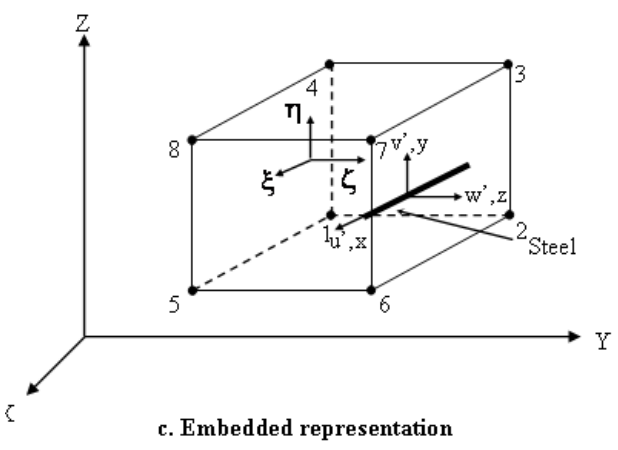

Fig. 3 Reinforcement representation type

Embedded Representation: The embedded representation is often used with high order isoparametric elements. The bar elements are assumed to be built into the brick elements. In this approach perfect bond is assumed between the reinforcing bars and the surrounding concrete. The stiffness of steel bars is added to that of the concrete to obtain the global stiffness matrix of the element. It is assumed that the bars are restricted to be parallel to the local coordinate axes $\xi$, $\eta$ and $\zeta$ of the brick element (Fig.(3.c)).

In the present work, the reinforcement is included within the properties of the 8-node brick solid65 elements (embedded representation) to include the reinforcement effect in the concrete structures, excluding the reinforcing bars that are crossing the joint, which are represented by using "bar Likn8 elements" (Discrete representation). In the two manners, the reinforcement is assumed to be capable of transmitting axial forces only, and perfect bond is assumed to exist between the concrete and the reinforcing bars.

Model Generation: Two different methods used in current study to generate a model: Solid model and direct generation. In solid modeling some one can describe the boundaries of the model, establish 
Am. J. Sci. Ind. Res., 2010, 1(3): 472-495

controls over the size and desired shape elements automatically, by contrast. In the direct generation method, determine the location of every node and size, shape and connectivity of every element prior to defining these entities in ANSYS model.

In this study the dome with large diameter $(50,70$ and $100)$ meter is analysis with rib and without, firstly the dome is plotted and meshed using solid65 with different thickness $(5,7$ and 10$) \mathrm{cm}$ as shown in Fig.(4).

Then the dome is reinforcement using steel element Link8 as shown Fig.(5).

The study is concerned on the effect of the ribs on the deflection of the dome. The section of the rib is taken as T- section as shown in Fig.(6).
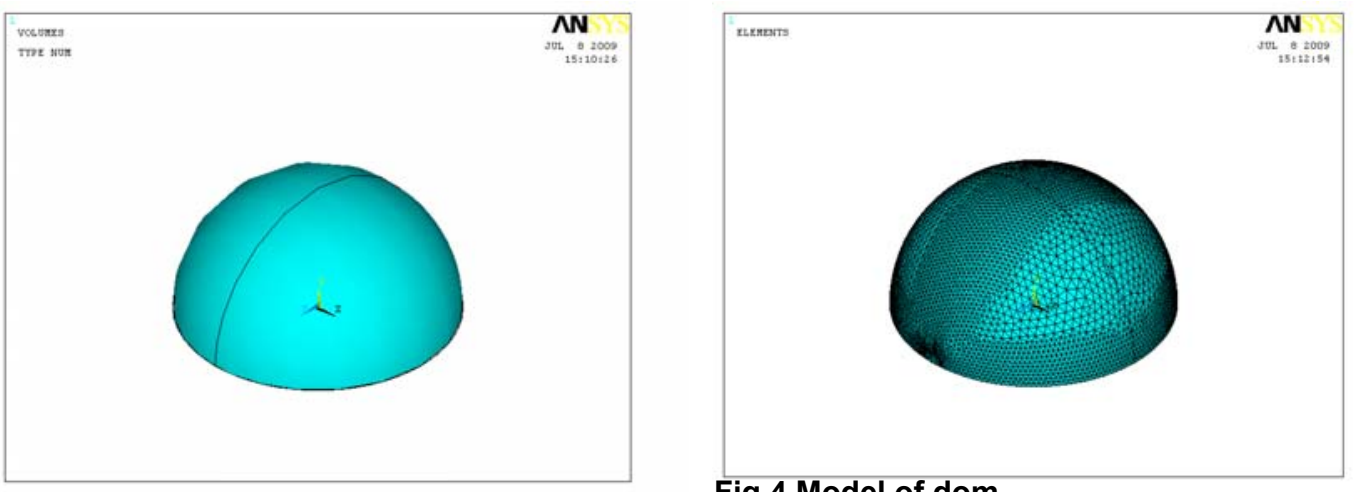

Fig 4 Model of dom
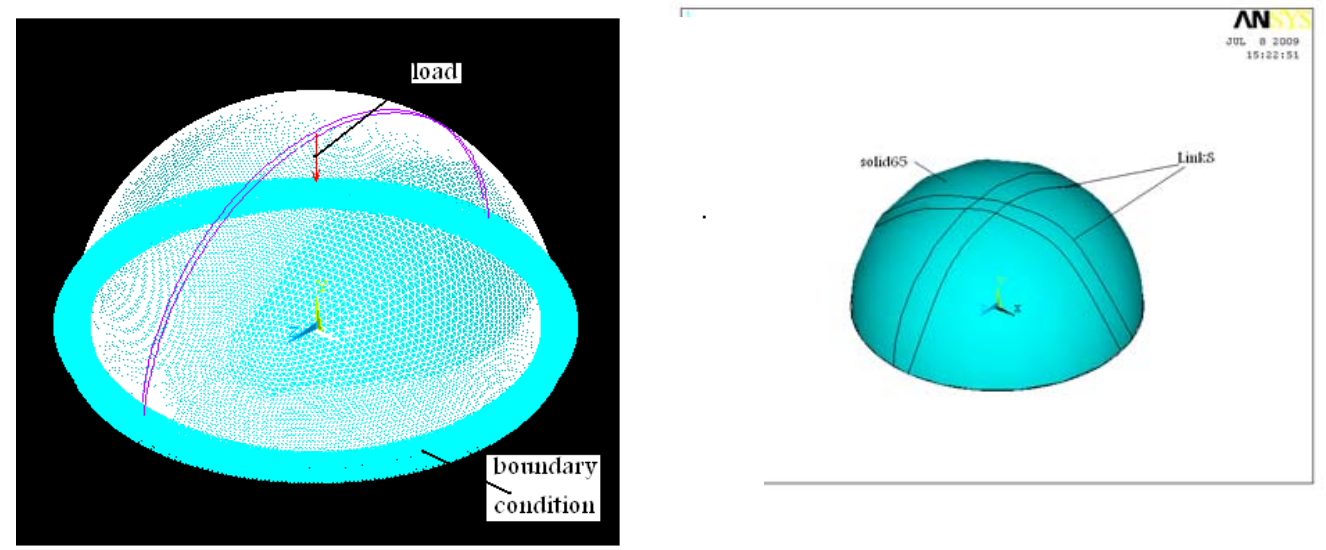

Fig.5 Reinforcement in the dome

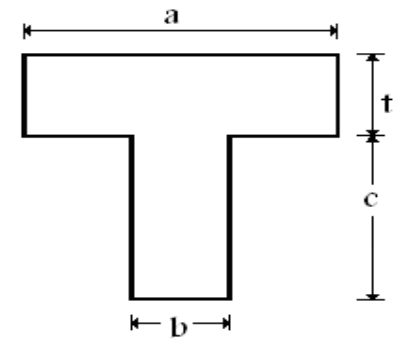

Fig $6 \mathrm{~T}$-section of the rib, $\mathrm{a}=0.6 \mathrm{~cm}, \mathrm{~b}=0.3 \mathrm{~cm}, \mathrm{c}=0.6 \mathrm{~cm}, \mathrm{t}=0.1 \mathrm{~cm}$

Three cases are studied, the first one is the dome with one rib, the second is the dome with two ribs and third one is the dome with three ribs, in the case of one rib, the rib is located half on the dome and in the 
Am. J. Sci. Ind. Res., 2010, 1(3): 472-495

second case the two ribs were crossed and the third case the arrangement of the ribs were two ribs cross and the third with 45 degree between the two ribs as shown in Fig.(7)

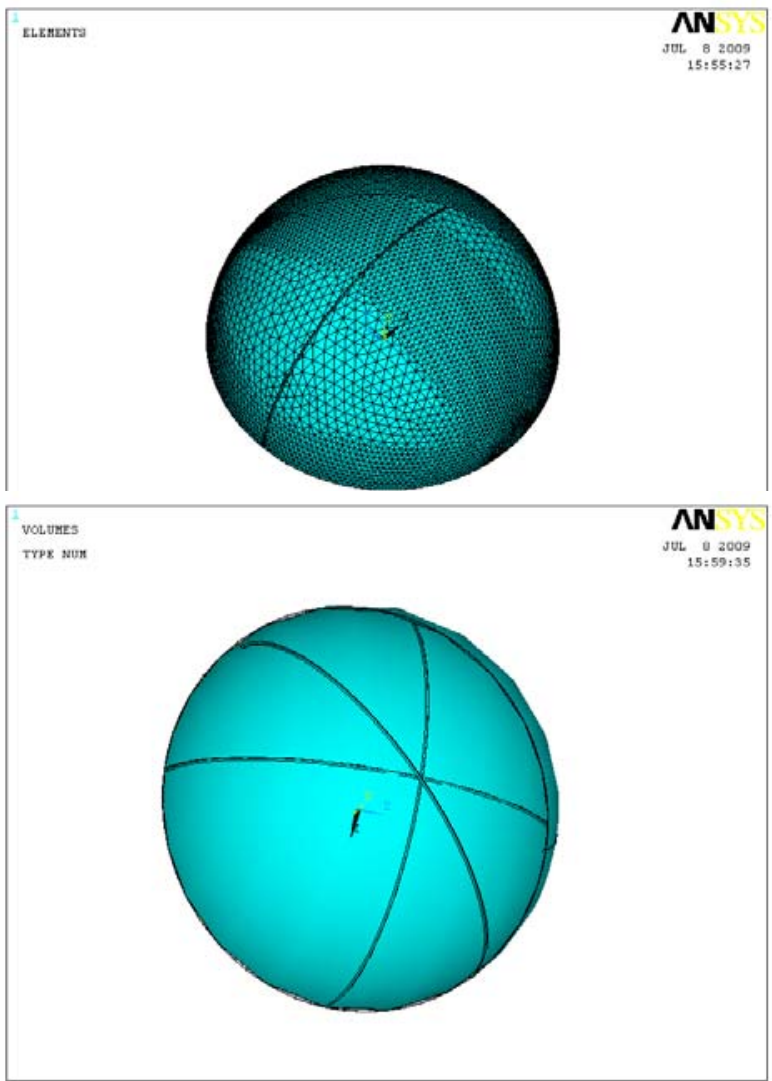

Several difficulties was attacked in the building of the model as shown Fig.(8).

Fig 7 Dome model with one, two and three ribs

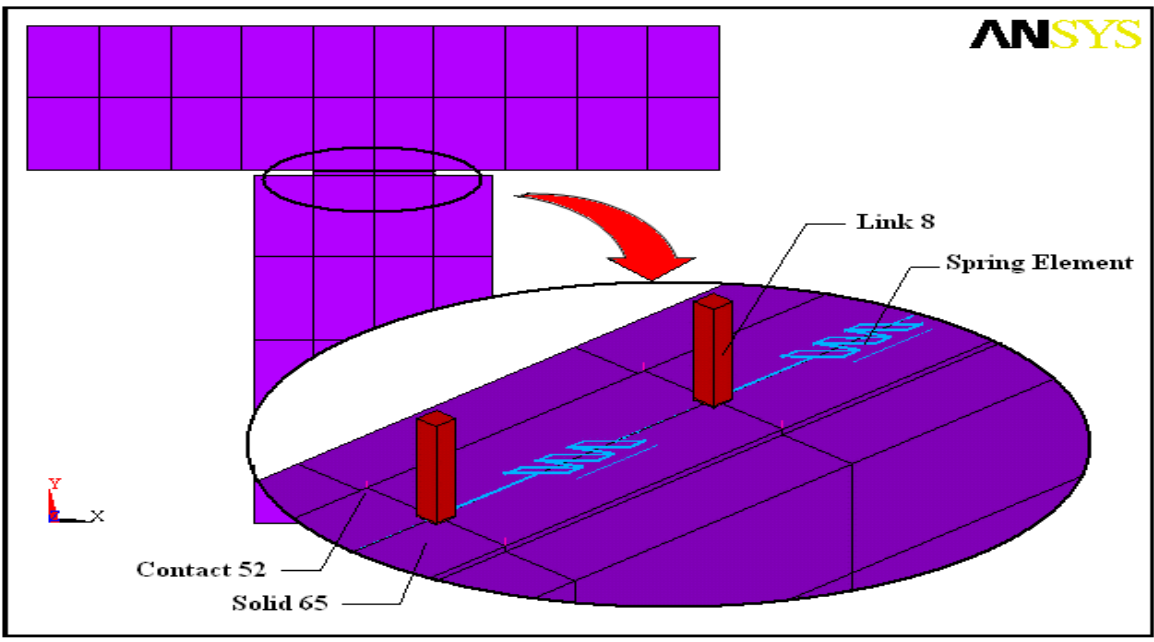

Fig.8 Interface elements modeling in ANSYS dome with pre-cats ribs and cast in place cover 
There are two major cases are studied, the first one is the rib embedded in the dome and in this case the rib is done by using direct generation using beam 188 with T-section while in the second case the T-section as an area and then dragging with path to form the rib, this steps is done with one and two ribs while in three ribs the transformation coordinates had been done to get the rib at 45 degree as shown in Fig.(9) (Hani, 2010). To connect the rib with the dome, the dowel is used which represented by link 8 as shown in Fig.(10).

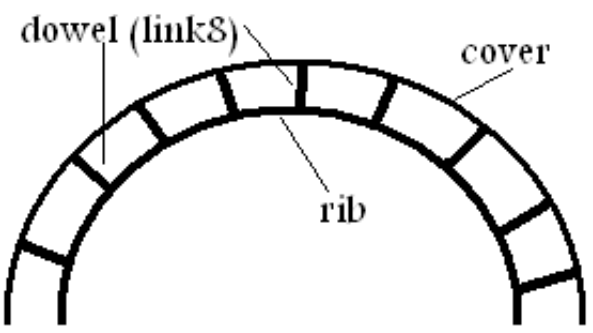

Fig.10 Dowel case

Fig 9Transformation coordinates (Hani,2010)

From Fig.(9) it can be deduced that

$$
\begin{aligned}
& \bar{x}=x-x_{1} \\
& \bar{y}=y-y_{1} \quad \ldots \ldots \ldots \ldots \ldots \ldots \ldots \ldots \ldots \ldots \ldots \ldots \ldots \ldots \ldots \ldots \ldots \ldots \\
& x n=x_{1}+\bar{x} \cos \theta-\bar{y} \sin \theta \\
& y n=y_{1}+\bar{x} \sin \theta-\bar{y} \cos \theta
\end{aligned}
$$

deflection values within the reinforced concrete dome. ANSYS results are then compared with the theoretical ones (David Billington,1990) "shell theory equations" which achieved good agreement.

Case One: Plain Dome (without ribs)

Description of Structure and Finite Element Modeling A $50 \mathrm{~m}$ reinforced concrete dome without ribs of $0.05 \mathrm{~m}$ cover thickness and subjected to a vertical downward point load, $\mathrm{P}=1150 \mathrm{~N} / \mathrm{m}^{2}$ applied at crown, is modeled by (101210) 8-node brick elements Solid65 to represent the concrete of the dome. The finite element mesh, boundary conditions and loading are all modeled by ANSYS12 system and shown in Figs.(11) and (12).

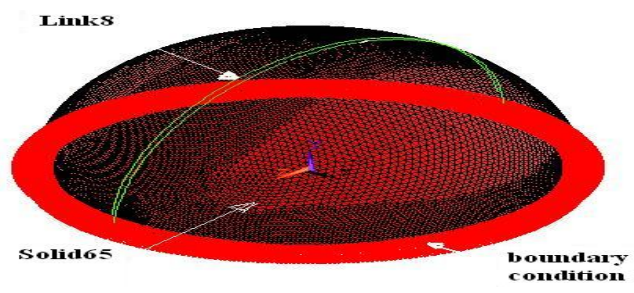

Fig.12 FE model of unribbed reinf. concrete dome 
Am. J. Sci. Ind. Res., 2010, 1(3): 472-495

Table 2.Comparison of stresses between FEA and theory from crown to bottom edge of dome.

\begin{tabular}{|c|c|c|c|c|}
\hline${ }^{*} \phi$, degrees & $\sigma_{\phi}, \mathrm{MPa}, \mathrm{FEA}$ & $\begin{array}{c}\sigma_{\phi}, \mathrm{MPa}, \\
\text { Shell Theory }\end{array}$ & $\sigma_{\theta}, \mathrm{MPa}, \mathrm{FEA}$ & $\begin{array}{c}\sigma_{\theta}, \mathrm{MPa}, \\
\text { Shell Theory }\end{array}$ \\
\hline 0 & -0.573 & -0.575 & -0.580 & -0.575 \\
\hline 15 & -0.576 & -0.585 & -0.530 & -0.525 \\
\hline 30 & -0.595 & -0.616 & -0.413 & -0.379 \\
\hline 45 & -0.642 & -0.673 & -0.185 & -0.139 \\
\hline 60 & -0.773 & -0.766 & 0.149 & 0.191 \\
\hline 75 & -0.934 & -0.913 & 0.592 & 0.615 \\
\hline 90 & -1.32 & -1.15 & 1.122 & 1.15 \\
\hline
\end{tabular}

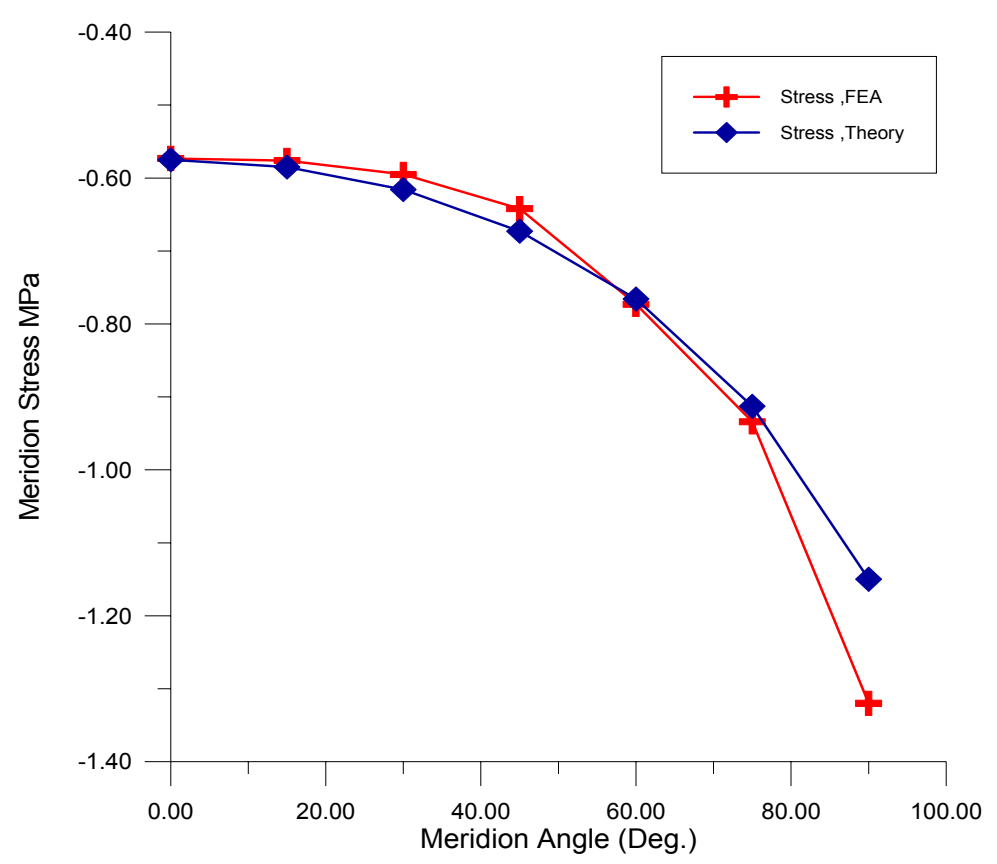

Fig.13 Comparison of FEA and shell theory with angle vs. meridion stress

${ }^{*} \phi$ is the angle between the vertical radius and the radius through the point at which stresses are calculated ${ }^{* *}+\mathrm{ve}$ is tension

The longitudinal reinforcing bars are embedded into the brick elements at their correct positions and modeled by Link8 finite element of ANSYS. Full Newton-Raphson method to carry out the nonlinear analysis is adopted. A displacement convergence criterion is used with tolerance of $(0.5 \%)$.

2- Presentation and Discussion of Results of Analysis

A) Normal Membrane Stress in the Meridiainal Direction $\sigma_{\phi}$

Those stress computed by the present FE-model and by the classical membrane theory of shell (David Billington,1990) are shown in table(2) and Fig.(13).
From observation of the previous table and figure is shown that very good agreement between the present finite element approach and the shell theory solution is obtained, specially for value of $\phi$ less than $77^{\circ}$, the average different in values of those stress for this range of angle $\phi$ value is $2.2 \%$, while the finite element model has given slightly higher values for meridional stress for small value of the angle $\phi(\geq 60)$ than those given by the analytical solution, this it rend has reversed for larger values of the angle $\phi>60$. This phenomena may be mainly due to elementary simplification of the membrane theory regarding ignoring bending stresses. 
Am. J. Sci. Ind. Res., 2010, 1(3): 472-495

B- Normal Membrane Stress in the Hoop

Direction; $\sigma_{\theta}$

Those stresses as computed by the present FEmodel and the membrane theory of shell for values of the angle $\phi$ ranging between $\left(0^{\circ}-90^{\circ}\right)$ are all shown in table(2) and Fig.(14) .

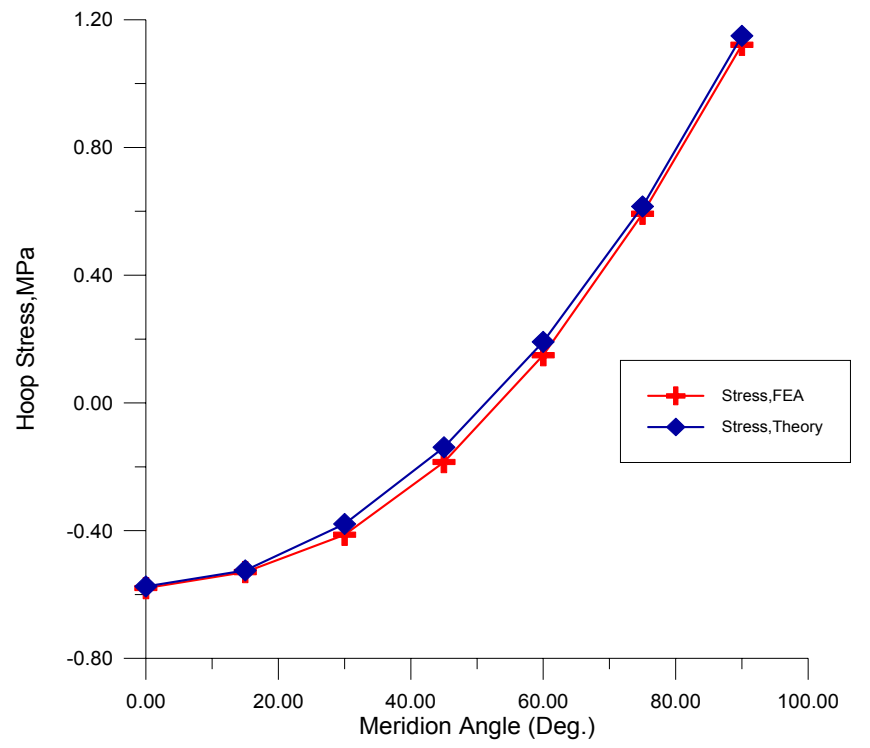

Fig.14 Comparison of FEA and shell theory with angle vs. hoop stress

Inspection of Fig.(14) clarifies the excellent agreement between the FE-model and the membrane shell theory computation for whole range of angle $\phi$ values. The average difference in value of those stress is $3.3 \%$. This excellent is fact reflect the high efficiency of the membrane theory in computing normal hoop stresses in axsysmmetric double curvature shells, since no bending stress in the hoop direction of such shell exists.

Case Tow: Monolithic Dome

\section{1- Description of Structure and Finite Element} Modeling

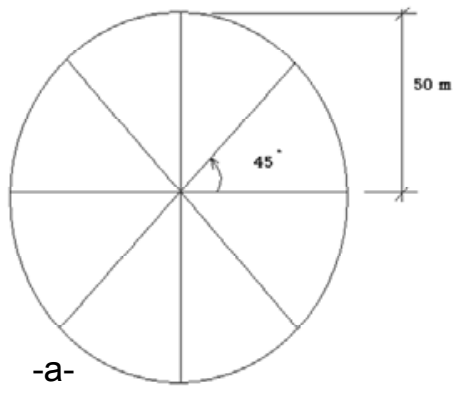

A $50 \mathrm{~m}$ reinforced concrete ribbed dome of $0.05 \mathrm{~m}$ cover thickness and content four ribs distribution each 45 degree, are subjected to a vertical downward point load, $\mathrm{P}=0.728 \mathrm{MPa}$ applied at crown, is modeled by (101210) 8-node brick elements Solid65 to represent the concrete of the dome and (330) 2node Beam188 element to represent the ribs of the dome. The finite element mesh, boundary conditions and loading are all modeled by ANSYS12 system and shown in Fig.(15).

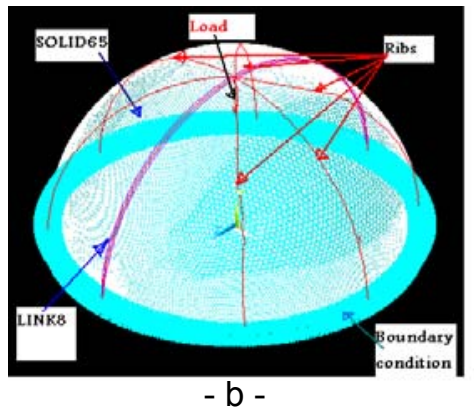

Fig.15 FE-Modeling of monlthich rib reinf. concrete dome (case(2))

The longitudinal reinforcing bars are embedded into the brick elements at their correct positions and modeled by Link8 finite element of ANSYS. Full
Newton-Raphson method to carry out the nonlinear analysis is adopted. A displacement convergence criterion is used with tolerance of $(0.5 \%)$. 


\section{2- Presentation and Discussions of Results}

A) Normal stresses in the three orthogonal direction $\sigma_{\mathrm{X}}, \sigma_{\mathrm{y}}, \sigma_{\mathrm{z}}$ versus of angle $\phi$, table(3) show the values of normal stress in the three orthogonal direction of the cartezian coordinate $\mathrm{x}, \mathrm{y}$ and $\mathrm{z}$ for seven locations in the dome at intersection, those value of stresses are obtained from the present finite element model with $x-y$ plane, those location specified seven point given in table(3) are those making $\phi$ angle of values $(0,15,30,45,60,75,90)$ degree.

Table 3 Stress and deflection from crown to the bottom

\begin{tabular}{|c|c|c|c|c|}
\hline$\phi$, degrees & $\sigma_{\mathrm{X}}, \mathrm{MPa}$ & $\sigma_{\mathrm{y}}, \mathrm{Mpa}$ & $\sigma_{\mathrm{Z}}, \mathrm{Mpa}$ & Deflection , mm \\
\hline 0 & -6.29 & 0.256 & -8.68 & -4.3 \\
\hline 15 & -0.367 & -0.607 & -2.68 & -1.1 \\
\hline 30 & 0.855 & -0.0964 & -0.423 & -0.13 \\
\hline 45 & 0.458 & -0.169 & 0.132 & -0.1 \\
\hline 60 & 0.285 & -0.145 & 0.0515 & -0.06 \\
\hline 75 & 0.16 & -0.146 & 0.0011 & -0.034 \\
\hline 90 & 0.0054 & -0.134 & 0.035 & -0.021 \\
\hline
\end{tabular}

Values of stresses in the three orthogonal directions (i.e. $\sigma_{\mathrm{X}}, \sigma_{\mathrm{y}}, \sigma_{\mathrm{Z}}$ ) which are recorded in table(3) above are all graphically plotted versus the angle $\phi$ and shown in Fig.(16) .

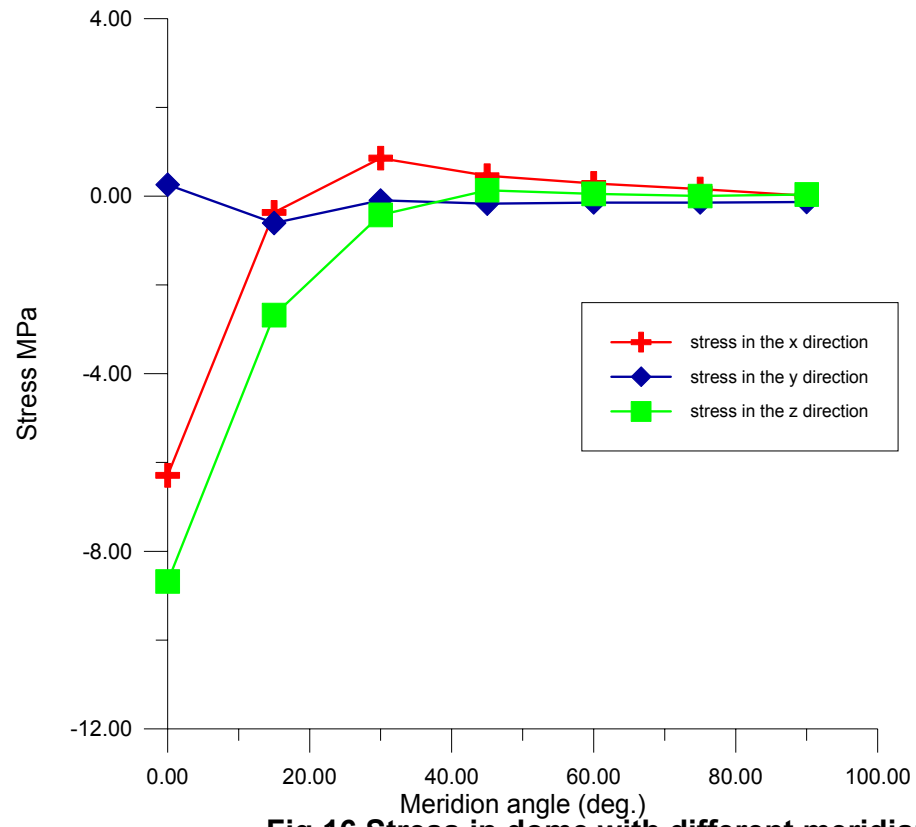

Fig.16 Stress in dome with different meridian angles

From the inspection of table(3) and Fig.(16) it seen that the values the normal $\operatorname{stress}\left(\sigma_{\mathrm{X}}\right)$ has a maximum compressive value at the crown (under the concentrated load) with moving along the meridional section in the $x-y$ plane (i.e. with increasing the value of angle $\phi$ from zero). It seen that the compressive value of $\sigma_{X}$ decreases gradually until became zero at $\phi$ angle equal $18^{\circ}$ beyond this location (i.e. with increasing the $\phi$ value beyond $18^{\circ}$ ) the $\sigma_{X}$ became tensile and increases rapidly until it reached its max. tensile value at $\phi$ angle equal $31^{\circ}$. Beyond the angle $\phi$ value $31^{\circ}$ the $\sigma_{X}$ value reduced slowly until its vanishes at angle $\phi$ value equal to $90^{\circ}$ (i.e. at the dome base) . 
Am. J. Sci. Ind. Res., 2010, 1(3): 472-495

The variation of the normal stress $\sigma_{\mathrm{y}}$ with angle $\phi$ ( at dome section in the $x-y$ plane) is quiet different from that of $\sigma_{\mathrm{x}}$. The variation of $\sigma_{\mathrm{y}}$ with angle $\phi$ is seemed uniform (i.e. extremely small variation of $\sigma_{\mathrm{y}}$ with angle $\phi$ ) this trend is quiet logical as the dome meridional slice within $x-y$ plane, act as an arch with two clamped edge and subjected to vertical downward point load at the crown. The curve representing the relation between the normal $\sigma_{\mathrm{Z}}$ and angle $\phi$ is clearly closed in its trend to the corresponding curve of $\sigma_{\mathrm{X}}$, with the $\sigma_{\mathrm{Z}}$ values smaller than their corresponding once. This fact may be attributed to the asysmmetric properties of the analysis shell. Figs.(17),(18) and (19) are shown the variation of each of the three normal membrane stress $\sigma_{\mathrm{X}}, \sigma_{\mathrm{y}}, \sigma_{\mathrm{Z}}$ over the whole outer surface of the analysis dome respectively. From these figures the similarity of the distribution $\sigma_{\mathrm{X}}$ and $\sigma_{\mathrm{Z}}$ stresses is quiet clear (with $90^{\circ}$ orientation about y-axis) this fact reflect the symmetric properties of the analysis dome.

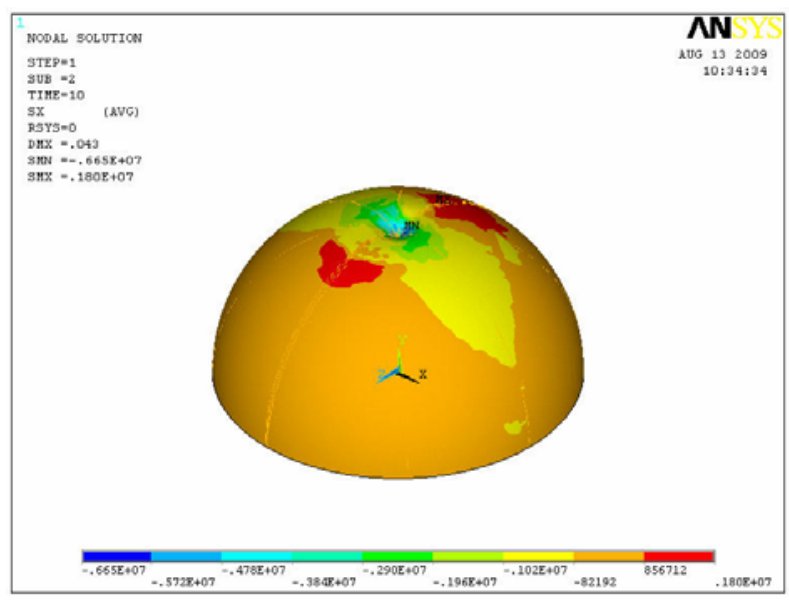

Fig.17 Stress in the $\mathrm{x}$ - direction

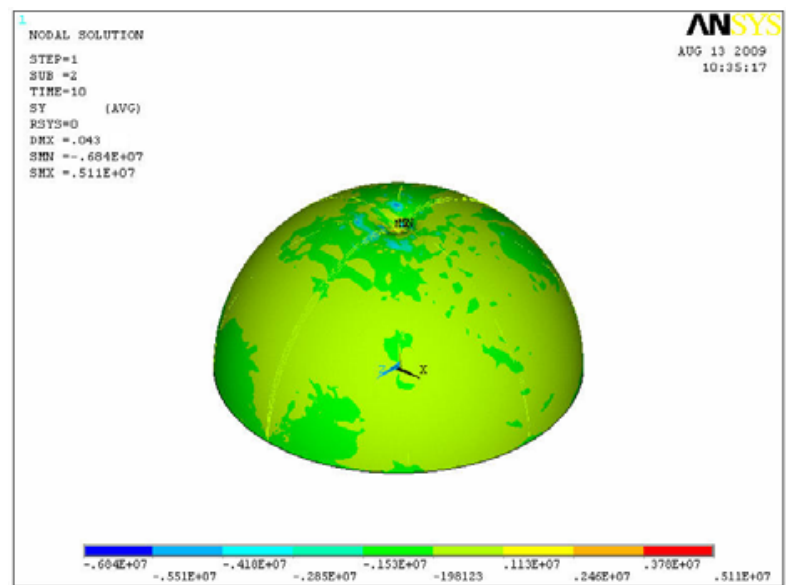

Fig.18 Stress in the $y$ - direction

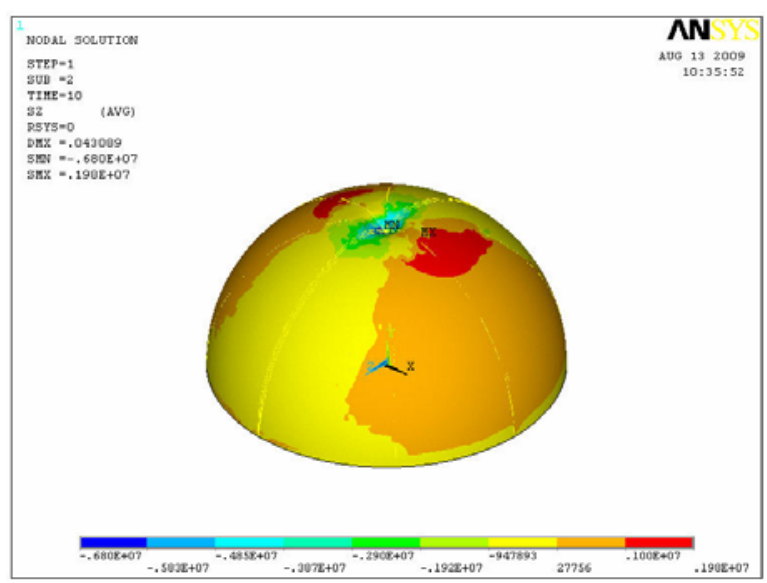

Fig.19 Stress in the z- direction

B) Vertical Deflection

Values of vertical displacement at specified location on dome surface at $x$-y plane which are shown in table(3) for the specified values of the meridional angle $\phi$ are all plotted in Fig.(20) versus the angle $\phi$. 
Am. J. Sci. Ind. Res., 2010, 1(3): 472-495

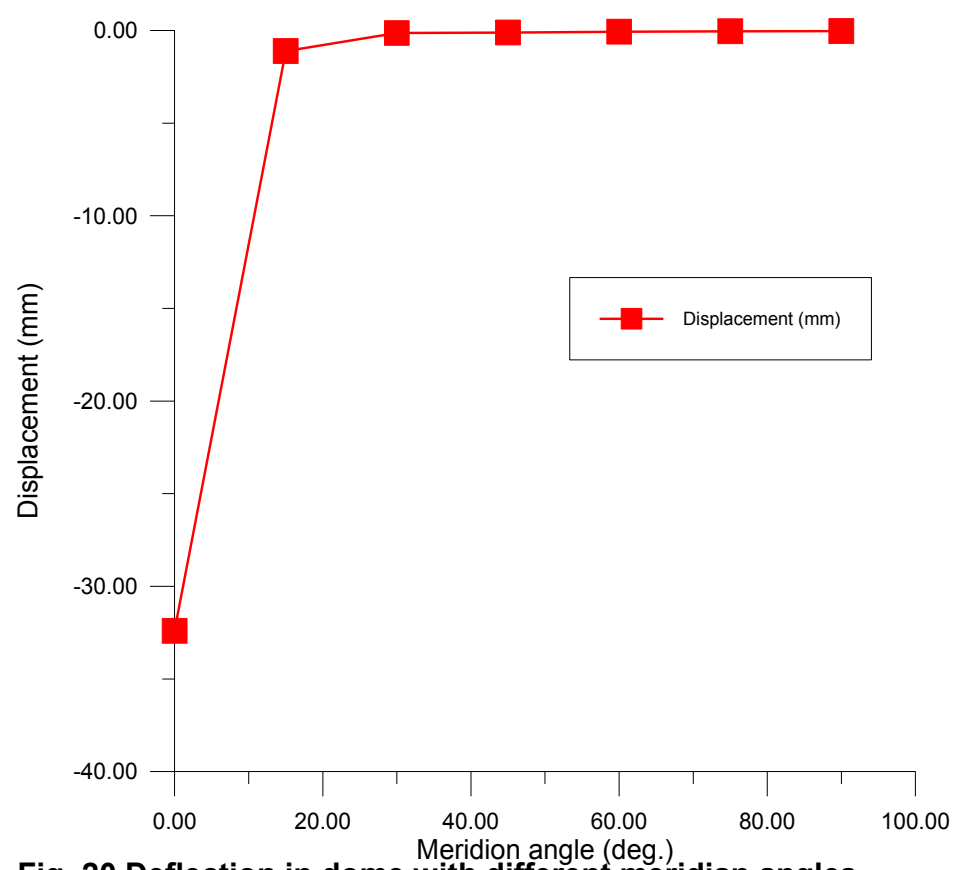

Fig. 20 Deflection in dome with different meridian angles

From this figure it easily observed that the vertical displacement has max. value at crown ( where the angle $\phi$ is zero) then the displacement reduce rapidly with the increase of value until it vanish for angle $\phi$ value from equal to $16^{\circ}$ after that angle $\phi$ value the vertical displacement remain zero till the dome base.

C) Fracture Pattern
Fig.(21) shows the fracture pattern of the analysis dome of the case two (concrete monolithic dome) subjected to the concentrated downward point load at crown. This fracture pattern is as failure stage of the dome. The inspection of that figure demonstrated the crashes concrete and compression within around the dome apex and the tensile failure cracking at rear the edge.

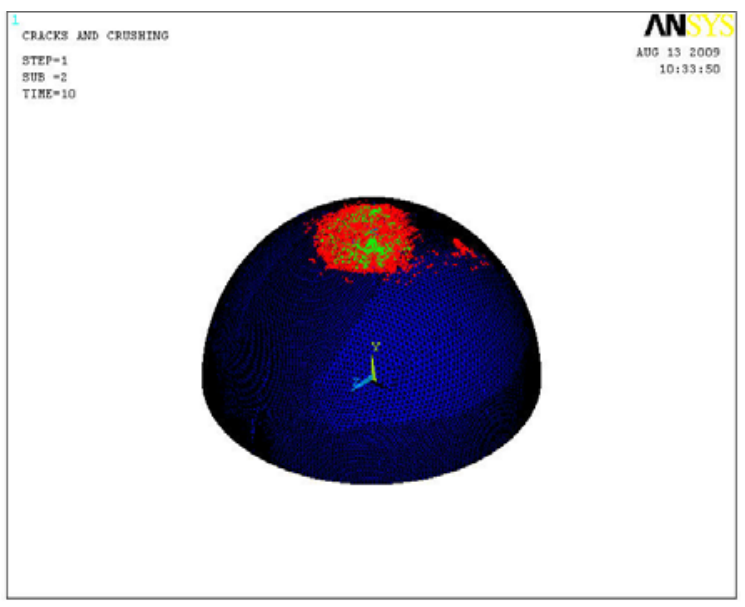

Fig. 21 Fracture pattern of dome case(2) at ultimate stage 
Case Three: Dome With Precast Rib and Cast in Place Cover

\section{1- Description of Structure and Finite Element} Modeling

A $50 \mathrm{~m}$ reinforced concrete ribbed dome of $0.05 \mathrm{~m}$ cover thickness and four ribs are subjected to a vertical downward point load, $\mathrm{P}=0.61 \mathrm{MPa}$ applied at crown, is modeled by (102970) 8-node brick elements solid65 to represent the concrete of the dome and (300) the effect of dowels which are passing through the interface between web and flange for rib is modeled by 300 nonlinear spring elements (combin14). The finite element mesh, boundary conditions and loading are all modeled by ANSYS system and shown in Fig.(22).

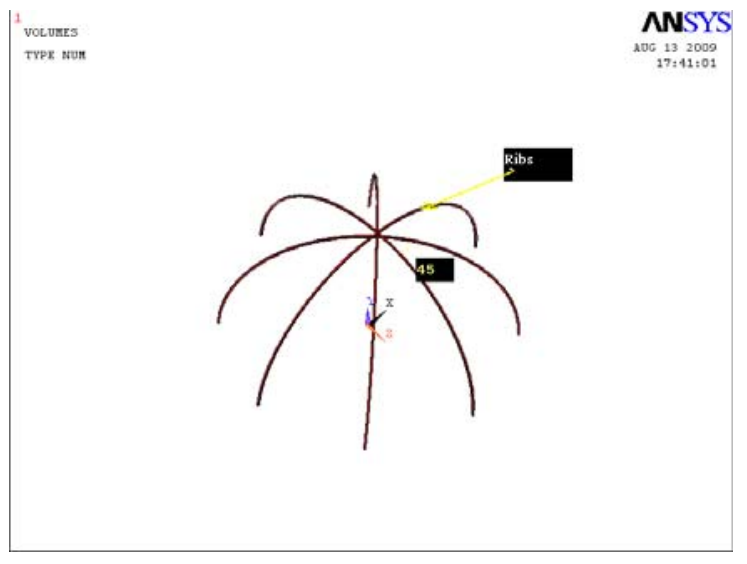

$-a-$

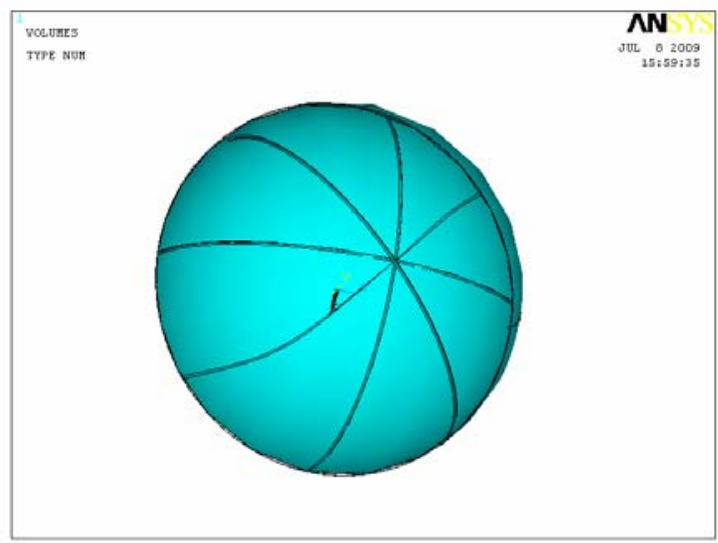

$-b-$

Fig. 22 Distribution of Dome ribs model (case(3))

\section{2- Presentation and Discussions of Results}

A) Normal stress in the three orthogonal direction $\sigma_{\mathrm{X}}, \sigma_{\mathrm{y}}, \sigma_{\mathrm{z}}$ versus of angle $\phi$, table(4) show the values of normal stress in the three orthogonal direction of the cartezian coordinate $x, y$ and $z$ for seven locations in the dome at intersection, those value of stresses are obtained from the present finite element model with $x-y$ plane, those location specified seven point given in table(4) are those making $\phi$ angle of values $(0,15,30,45,60,75,90)$ degree.

Values of stresses in the three orthogonal directions (i.e. $\left.\sigma_{\mathrm{x}}, \sigma_{\mathrm{y}}, \sigma_{\mathrm{z}}\right)$ which are recorded in table(4) above are all graphically plotted versus the angle $\phi$ and shown in Fig.(23).

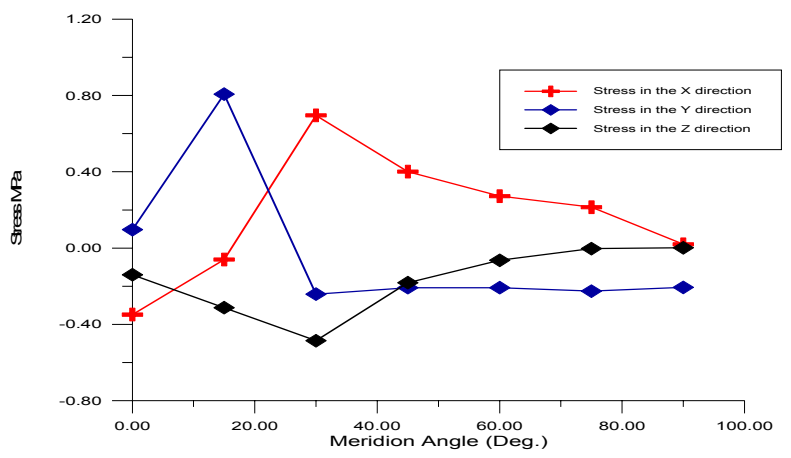

Fig.23 Stress in dome with different meridian angles 
Am. J. Sci. Ind. Res., 2010, 1(3): 472-495

Table (4): Stress and deflection from crown to the bottom

\begin{tabular}{|c|c|c|c|c|}
\hline$\phi$, degrees & $\sigma X, \mathrm{MPa}$ & $\sigma y, \mathrm{MPa}$ & $\sigma z, \mathrm{Mpa}$ & Deflection , mm \\
\hline 0 & -.349 & 0.0965 & -0.14 & -4.3 \\
\hline 15 & -0.00604 & 0.807 & -313 & -0.78 \\
\hline 30 & 0.696 & -0.242 & -0.486 & -0.48 \\
\hline 45 & 0.401 & -0.208 & -0.182 & -0.27 \\
\hline 60 & 0.272 & -0.208 & -0.064 & -0.016 \\
\hline 75 & 0.214 & -0.226 & -0.0031 & -0.0056 \\
\hline 90 & 0.0199 & $-0 . .206$ & 0.0015 & -0.0013 \\
\hline
\end{tabular}

From the inspection of table(4) and Fig.(23), it seen that the values the normal stress has it maximum compressive value at the crown (under the concentrated load ) with moving along the meridional section in the $x-y$ plane (i.e. with increasing value of angle $\phi$ from zero). It seen that the compressive value of $\sigma_{\mathrm{X}}$ decreases gradually until became zero at $\phi$ angle equal $20^{\circ}$ beyond this location (i.e. with increasing $\phi$ value beyond $20^{\circ}$ ) the $\sigma_{X}$ became tensile and increases rapidly until it reached its max. tensile value at $\phi$ angle equal $30^{\circ}$. Beyond angle $\phi$ value $30^{\circ}$ the $\sigma_{\mathrm{X}}$ value reduced slowly until its vanishes at angle $\phi$ value equal to $90^{\circ}$ (i.e. at the dome base) .

The variation of the normal stress $\sigma_{\mathrm{y}}$ with angle $\phi$ ( at dome section in the $x-y$ plane) is quiet different from that of $\sigma_{\mathrm{X}}$. The variation of $\sigma_{\mathrm{y}}$ with angle $\phi$ is seemed uniform (i.e. extremely small variation of $\sigma_{\mathrm{y}}$ with angle $\left.\phi\right)$ this trend is quiet logical as the

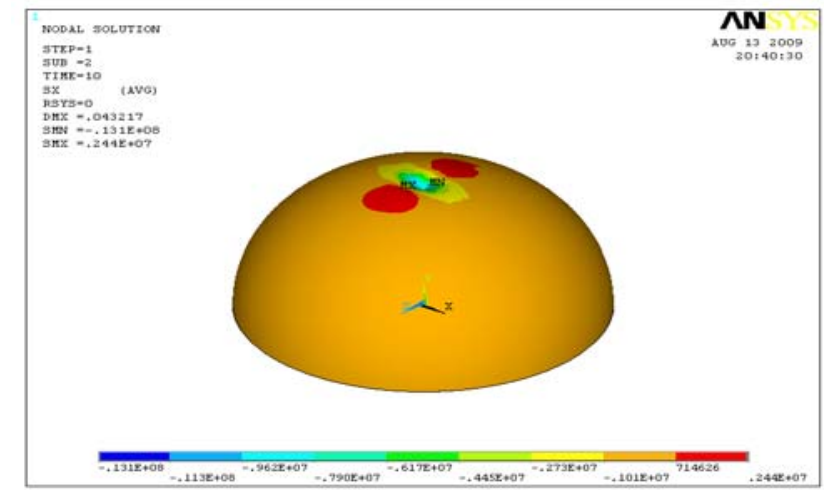

Fig 24 Stress in the $x$ direction dome meridional slice within $\mathrm{x}-\mathrm{y}$ plane, act as an arch with two clamped edge and subjected to vertical downward point load at the crown. The curve representing the relation between the normal $\sigma_{\mathrm{Z}}$ and angle $\phi$ is clearly closed in its trend to the corresponding curve of $\sigma_{\mathrm{X}}$, with the $\sigma_{\mathrm{Z}}$ values smaller than their corresponding once. This fact may be attributed to the asysmmetric properties of the analysis shell.

Figs.(24),(25) and (26) show the variation of each of the three normal membrane stress $\sigma_{\mathrm{X}}, \sigma_{\mathrm{y}}, \sigma_{\mathrm{Z}}$ over the whole outer surface of the analysis dome respectively. From these figures the similarity of the distribution $\sigma_{\mathrm{X}}$ and $\sigma_{\mathrm{Z}}$ stresses is quiet clear (with $90^{\circ}$ orientation about $y$ - axis) this fact reflect the symmetric properties of the analysis dome.

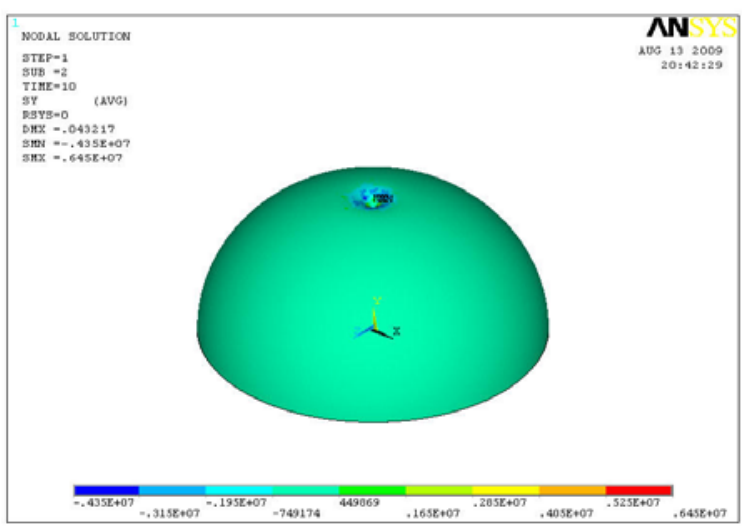

Fig.25 Stress in the y direction 
Am. J. Sci. Ind. Res., 2010, 1(3): 472-495

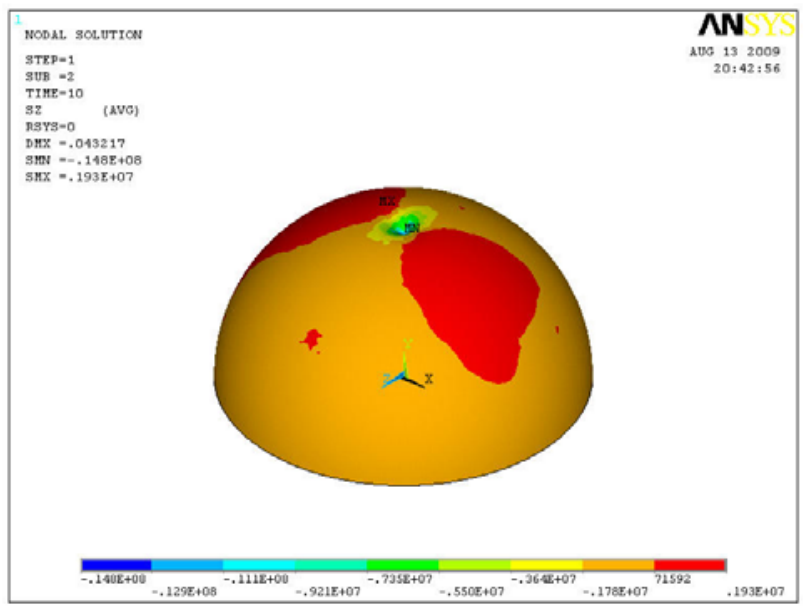

Fig. 26 Stress in the $z$ direction

B) Vertical Deflection

Values of vertical displacement at specified location on dome surface at $\mathrm{x}-\mathrm{y}$ plane which are shown in table(4) for the specified values of the meridional

angle $\phi$ are all plotted in Fig.(27).versus the angle $\phi$.

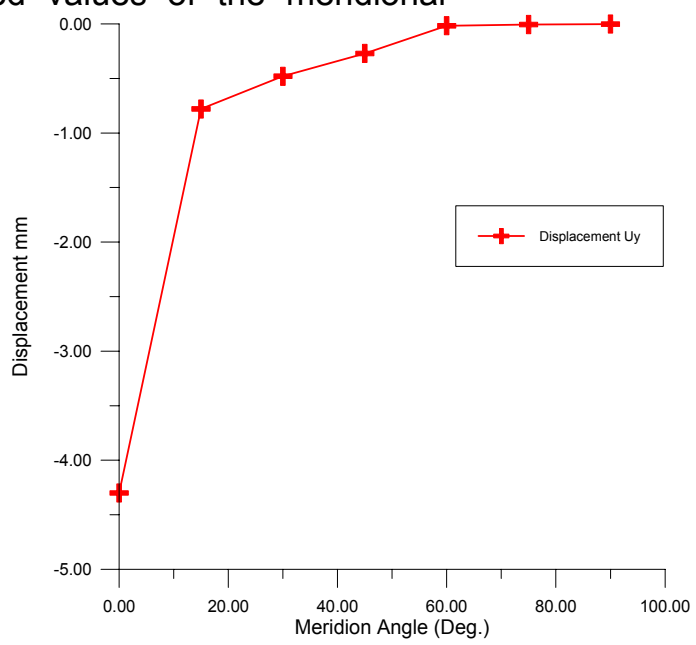

Fig. 27 Deflection in dome with different meridian angles

From this figure it easily observed that the vertical displacement has max. value at crown (where the angle $\phi$ is zero) then the displacement reduce rapidly with the increase of value until it vanish for angle $\phi$ value from equal to $90^{\circ}$ the dome base.

C) Fracture Pattern
Fig.(28) shows the fracture pattern of the analysis dome of the case three, subjected to the concentrated downward point load at crown, this fracture pattern is as failure stage of the dome. The inspection of that figure demonstrated the crashes concrete and compression within around the dome apex and the tensile failure cracking at rear the edge. 
Am. J. Sci. Ind. Res., 2010, 1(3): 472-495

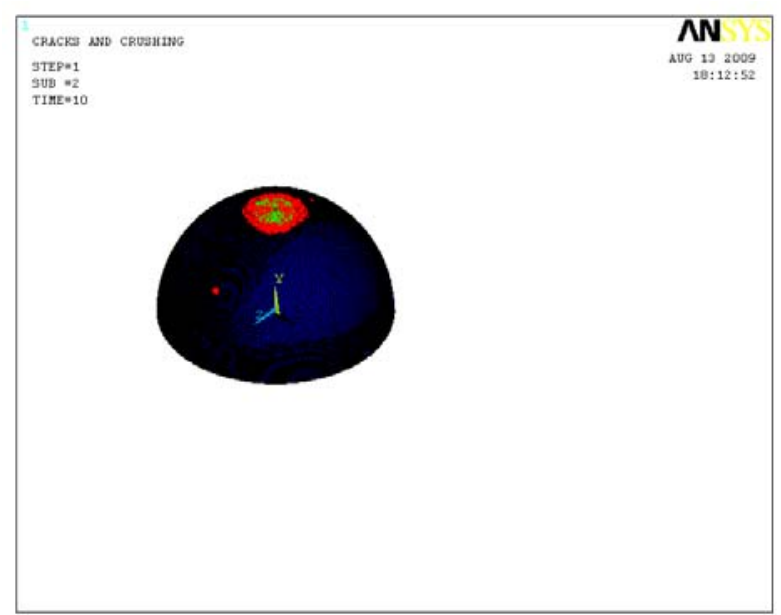

Fig.28 Fracture pattern of dome case(3) at ultimate stage

\section{Parametric Study}

Based on the present finite element model by ANSYS12, a parametric study was performed to investigate the influence of several important parameters on the behavior of concrete dome. The parameters studied can be summarized as follows:

1. Diameter of dome

2. Number of ribs .

3. Percentage of steel across the interface.

4. Compressive strength of concrete.

5. Cover thickness.

The effect of each of the above-mentioned parameters on the behavior of the concrete dome is discussed below.

\section{R.C Dome without Ribs:}

\section{1 -Effect of Diameter of Dome}

Dome of different diameters have been considered to study this effect on the behavior of the load-deflection curve. Fig.(29) shows the load-deflection curve at the crown of the dome with different diameter as determined by the present ANSYS model .The selected values of dome diameter are $50 \mathrm{~m}$ and $150 \mathrm{~m}$, in addition to the original diameter value; $100 \mathrm{~m}$. With respect to the original diameter; $100 \mathrm{~m}$, the $50 \mathrm{~m}$ diameter, caused a decrease in the ultimate load by about $(45.6 \%)$.

Similarly, the $150 \mathrm{~m}$ diameter, caused an increase in the ultimate load by about (54\%) relative to the original case (of $100 \mathrm{~m}$ diameter).

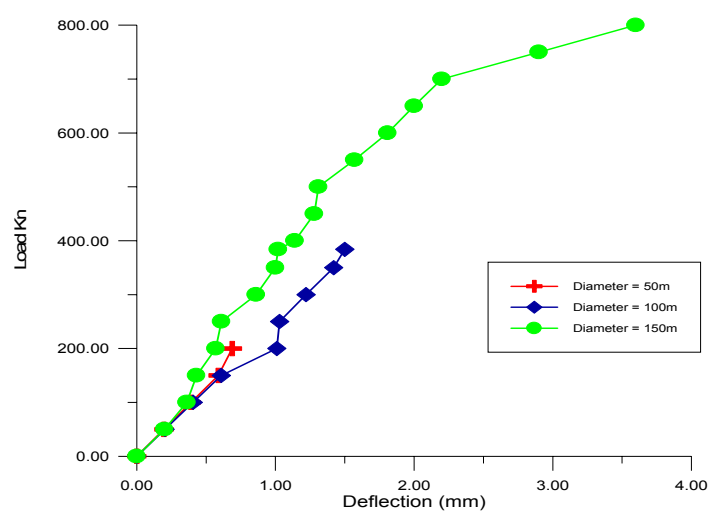

Fig. 29 Load-deflection relationships at crown three un ribbed dome (case(1)) showing effect of diameter value.

\section{2- Effect of Compressive Strength of Concrete:}

Fig.(30) shows the load-deflection curves at the crown for un ribbed dome (case(1)) of various concrete compressive strength values. Based on the results of that analysis, the following effects have 
Am. J. Sci. Ind. Res., 2010, 1(3): 472-495

occurred relative to the load-deflection relationships for the original $f^{\prime} c$ value $(30 \mathrm{MPa})$ :

i) Using $f^{\prime} c=25 \mathrm{MPa}$ for dome concrete, caused a decrease in the ultimate load by $(9 \%)$.

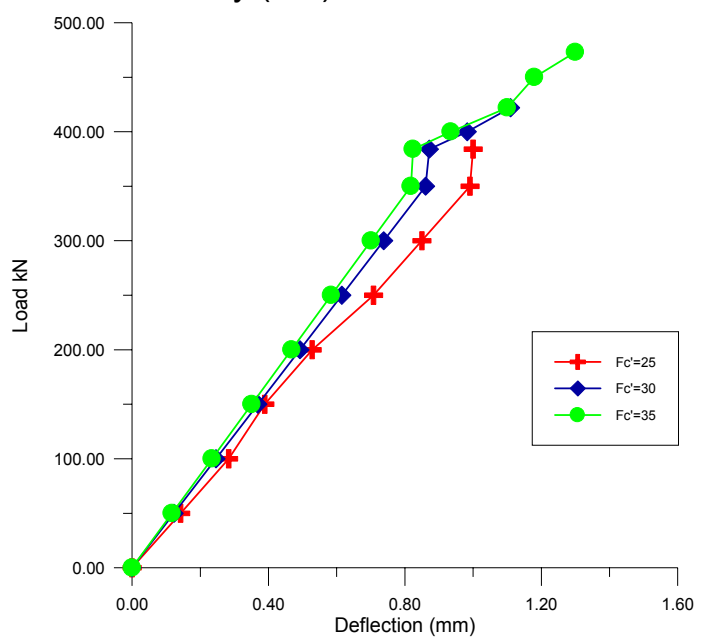

Fig. 30 Load-deflection relationships at crown for three un ribbed dome (case(1)) showing effect of compressive strength of concrete value.

\section{3-Effect of the cover thickness:}

Fig.(31) shows the response of deflection for various thicknesses of cover for concrete dome. Based on the results of the analysis, the following effects have resulted relative to the original cover thicknesses; $70 \mathrm{~mm}$. ii) The increase of $f^{\prime} c$ value to $35 \mathrm{MPa}$, caused an increase in the ultimate load by $(10.7 \%)$. i) Using thickness value $\mathrm{t}=50 \mathrm{~mm}$, caused a $6.5 \%$ decrease in the ultimate load.

ii) On the other hand, increasing cover thicknesses to $100 \mathrm{~mm}$ cased a $17.8 \%$ increase in the ultimate load value.

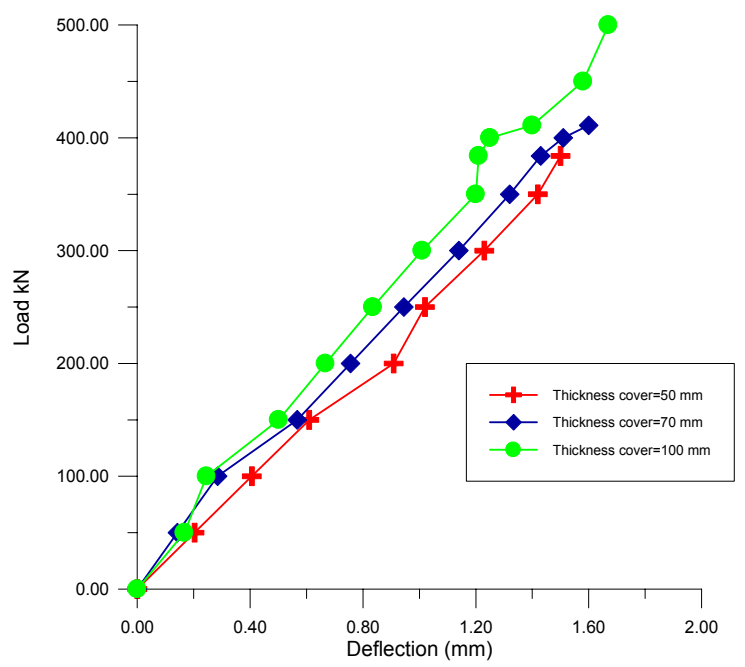

Fig. 31 Load-deflection relationships at crown for three un ribbed dome (case(1)) showing effect of the cover thickness value.

Monolithic R.C. Ribbed Dome:

1- Effect of Diameter of dome
Three dome with different dome diameter value each containing two ribs-have been considered to study this effect on the load-deflection relationships. 
Fig.(32) shows the load-deflection curves at the crown of the two ribbed dome with different diameter .The selected value diameter values were 40,70 and $100 \mathrm{~m}$.
With respect to the original diameter; $70 \mathrm{~m}$, using a $50 \mathrm{~m}$ diameter value, caused a decrease in the ultimate load by $(44.4 \%)$. Similarly, the increase diameter value to $150 \mathrm{~m}$, caused an increase in the ultimate load by $(16.9 \%)$.

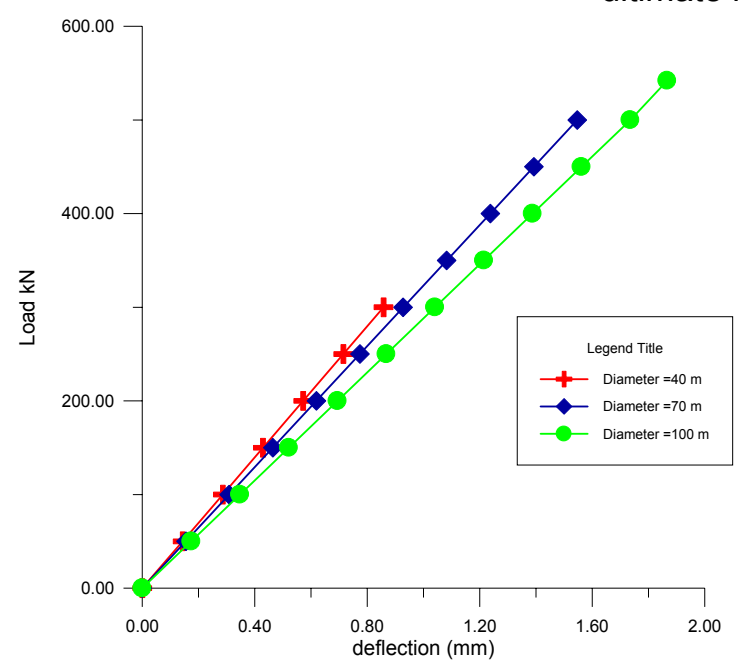

Fig. 32 Load-deflection relationships at crown for three ribbed dome (case(2)) showing effect of diameter value

\section{2- Effect of Number of Ribs}

Three ribbed monolithic domes with different numbers of ribs have been considered to study this effect on the load-deflection relationships.

Fig.(33) shows the load-deflection curves at the crowns of three ribbed monolithic domes of different numbers of ribs. The selected numbers are 0 (without ribs), 2 and 4 ribs. With respect to the original number of ribs; two; the removal of ribs, caused a $24.4 \%$ decrease in the ultimate load. On the other hand, increasing the number of ribs to four ,cased a $25.5 \%$ increase in the ultimate load.

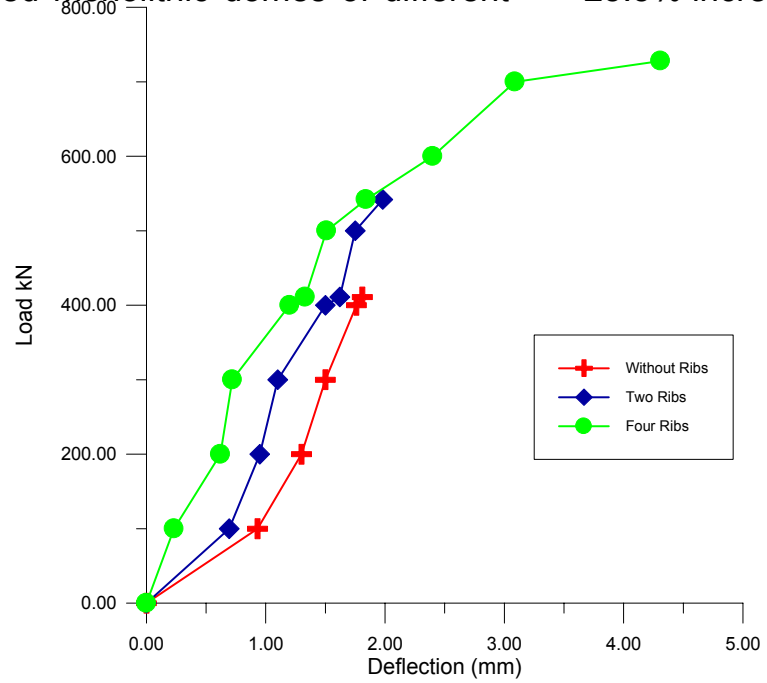

Fig. 33 Load-deflection relationships at crown for three ribbed dome (case(2)) showing effect of number of ribs .

\section{3 -Effect of Compressive Strength of Concrete} Fig.(34) shows the load-deflection curves for various concrete compressive strength values of ribbed monolithic dome each having two ribs.
Using concrete of $25 \mathrm{MPa}, f^{\prime} c$ value relative to the original $f^{\prime} c$ value; $30 \mathrm{MPa}$, caused a $11 \%$ decrease in the ultimate load. 
Am. J. Sci. Ind. Res., 2010, 1(3): 472-495

On the contrary, the increase of $f^{\prime} c$ value to 35 $\mathrm{MPa}$, cause a $7.5 \%$ increase in the ultimate load value relative to the original $f^{\prime} c$ value; $30 \mathrm{MPa}$, caused a $11 \%$ decrease in the ultimate load.

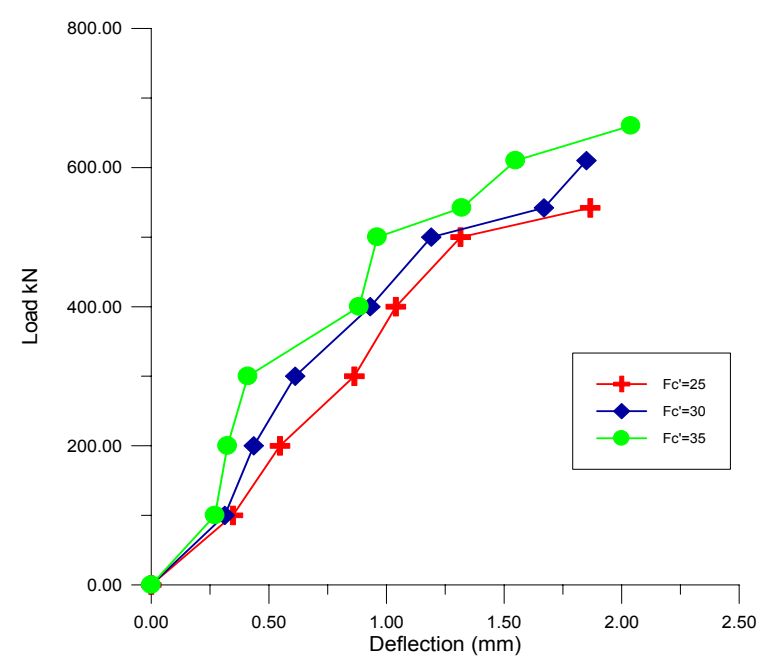

Fig.34 Load-deflection relationships at crown for three ribbed dome (case(2)) showing effect of compressive strength of concrete value

\section{4 -Effect of the Cover Thickness}

Fig.(35) shows the response of deflection for various thicknesses of cover for ribbed monolithic concrete dome each having two ribs. Relative to the original cover thickness $(70 \mathrm{~mm})$, when the thickness $(\mathrm{t})$ equal to $50 \mathrm{~mm}$ is used, the ultimate load is decrease by $(11.7 \%)$. However the increase of cover thickness to $100 \mathrm{~mm}$ cases a $17.9 \%$ increase in the ultimate load capacity, relative to the original cover thickness (70mm).

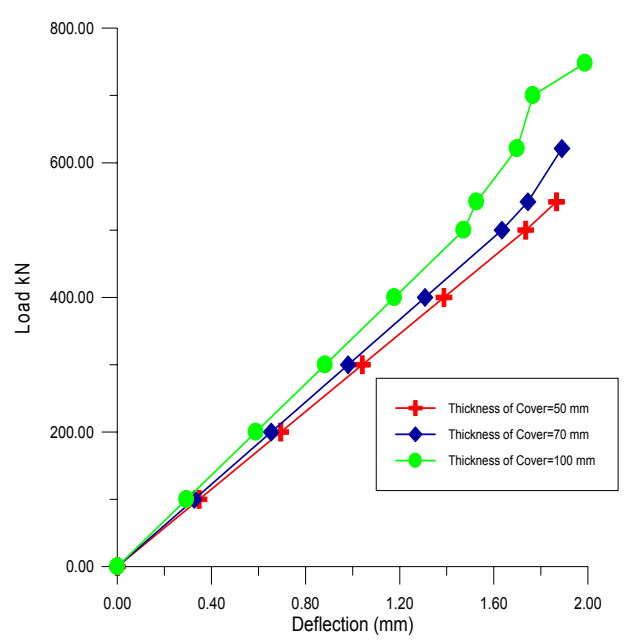

Fig.35 Load-deflection relationships at crown for three ribbed dome (case(2)) showing effect of the cover thickness.

\section{Dome with Pre-cast Concrete Ribs and Cast in}

\section{Place Concrete Cover}

\section{1 - Effect of Diameter of dome}

Dome (case(3)) with different diameter values each containing four ribs have been considered to study this effect on the load-deflection relationships.
Fig.(36) shows the load-deflection curves at the crowns three dome of this type varying in their diameters .The selected diameters values were 50 , 100 and $150 \mathrm{~m}$. Relative to the original diameter value; $100 \mathrm{~m}$, using $50 \mathrm{~m}$ diameter value, caused a $12.9 \%$ decrease in the ultimate load capacity. On the other side, the increase of diameter to $150 \mathrm{~m}$, caused 
Am. J. Sci. Ind. Res., 2010, 1(3): 472-495

a $17.6 \%$ increase in the ultimate load capacity of the

dome

of

$100 \mathrm{~m}$

diameter

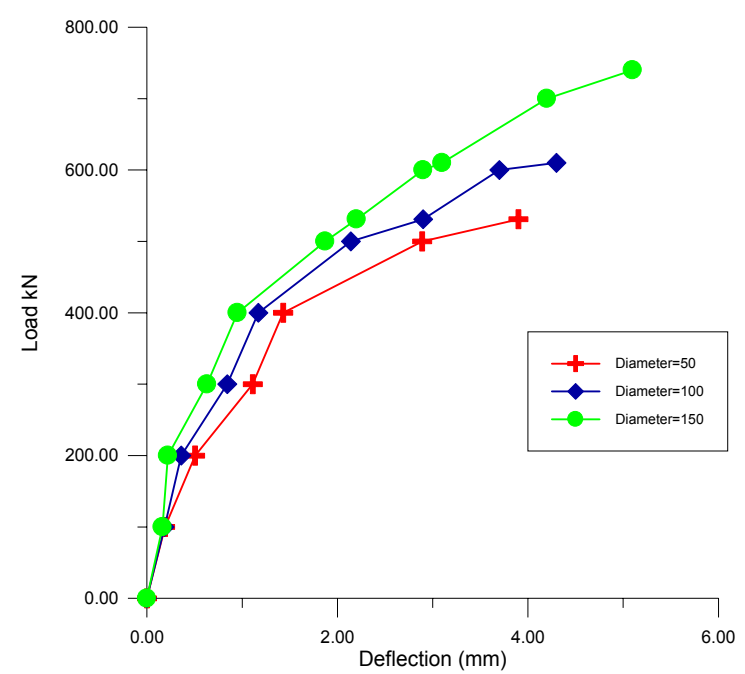

Fig.36 Load-deflection relationships at crown for three ribbed dome (case(3)) showing effect of Diameter

\section{2- Effect of number of ribs}

Dome (case(3)) with different numbers of ribs have been considered to study this effect on the loaddeflection relationships. Fig.(37) shows the loaddeflection curves at the crown of the pre-cast concrete ribs and cast in place concrete cover of different numbers of ribs. The selected numbers are:
0 (without ribs), 2 and 4 ribs. With respect to the original number of ribs; two; the removal of ribs caused a $17.8 \%$ decrease in the ultimate load capacity. On the other hand, increasing the number of ribs to four, caused a $18 \%$ increase in the ultimate load.

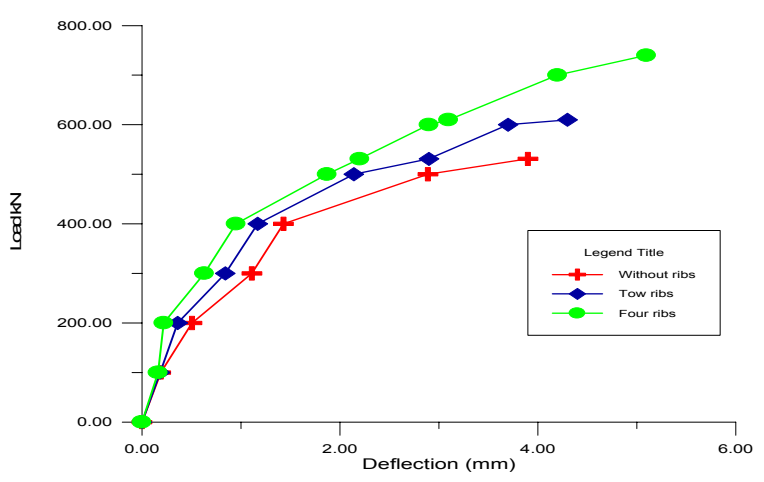

Fig. 37 Load-deflection relationships at crown for three ribbed dome (case(3)) showing effect of number of ribs.

\section{3- Effect of Compressive Strength of Concrete:}

Fig.(38) shows the load-deflection curves for various concrete compressive strength values of dome with pre-cast concrete ribs and cast in place concrete cover having four ribs . Using concrete of 25 and 20 $\mathrm{MPa}, f^{\prime} c$ values relative to the original $f^{\prime} c$ value; $30 \mathrm{MPa}$, caused a $4 \%$ and $7 \%$ respectively ,decrease in the ultimate load capacity. On the contrary, the increase of $f^{\prime} c$ value to 35 and 40 $\mathrm{MPa}$, cause a $5 \%$ and $10 \%$ respectively increase in the ultimate load capacity value relative to the original $f^{\prime} C$ value; $30 \mathrm{MPa}$. 
Am. J. Sci. Ind. Res., 2010, 1(3): 472-495

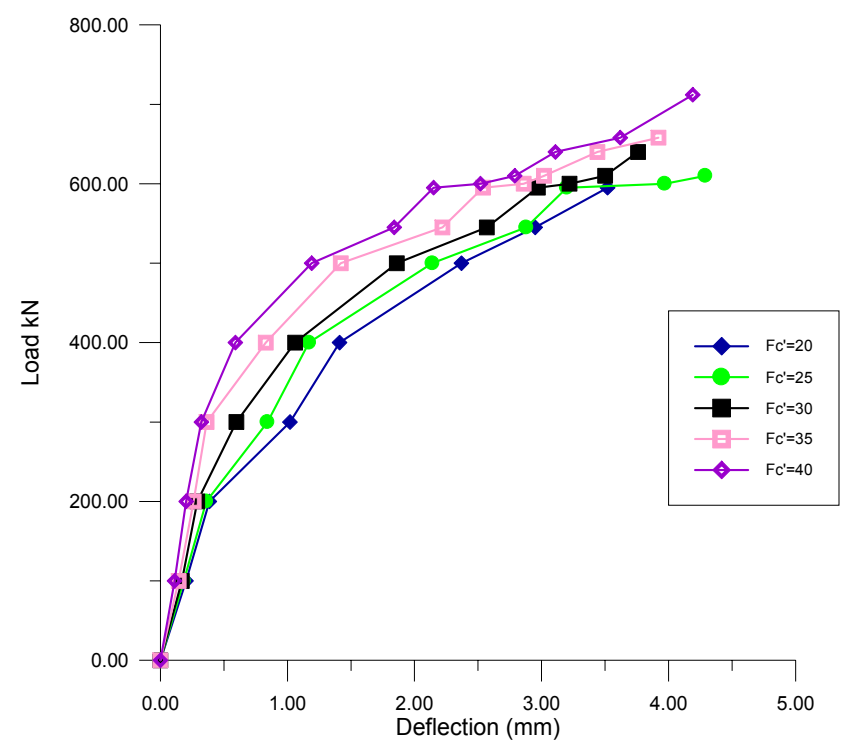

Fig. 38 Load-deflection relationships at crown for ribbed dome (case(3)) showing effect of concrete compressive strength values.

\section{4 - Effect of the Cover Thickness}

Fig. (39) shows the response of deflection for various thicknesses of cover for dome(case 3) with pre-cast concrete ribs and cast in place concrete cover having four ribs. Relative to the original cover thickness $(70 \mathrm{~mm})$, when the thickness equal to
$50 \mathrm{~mm}$ is used, the ultimate load is decrease by $(13.5 \%)$. However the increase of cover thickness to $100 \mathrm{~mm}$ cases a $13.9 \%$ increase in the ultimate load capacity, relative to the original cover thickness (70mm).

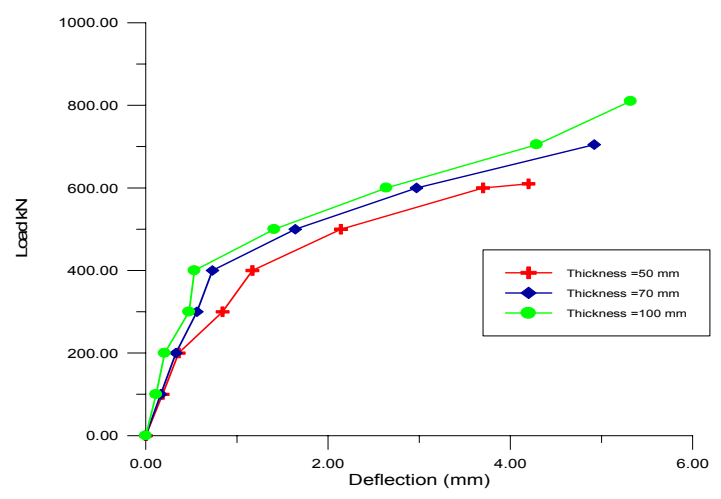

Fig. 39 Load-deflection relationships at crown for ribbed dome (case(3)) showing effect of the cover thickness.

5- Effect Percentage of steel across the interface

To study the effect steel percentage across the joint of dome (case(3)) with pre-cast concrete ribs and cast in place concrete cover having four ribs with different percentages $(\rho) 0,0.18,0.32$ and 0.46 (where $\rho=$ steel percentage across the joint (area of steel crossing the joint/ area of joint)). The results from Fig.(40) indicate that a large difference in failure load is noticed by using different steel percentage across the joint. A $30 \%, 60 \%$, and $100 \%$ decrease of steel ratio caused a decrease of $15.9 \%, 29 \%$ and $38 \%$ respectively in the ultimate load capacity. 
Am. J. Sci. Ind. Res., 2010, 1(3): 472-495

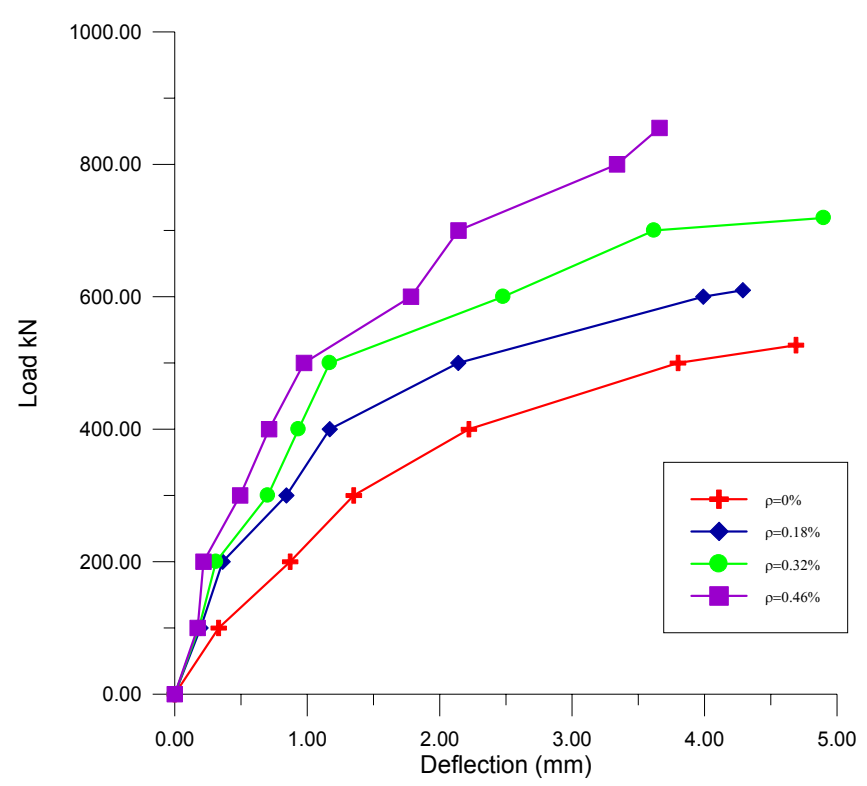

Fig.40 Load-deflection relationships at crown for ribbed dome (case(3)) showing effect of Percentage of steel across the interface.

\section{CONCLUSIONS}

1- The present finite element model has given very good accuracy in computing the membrane normal stresses $\sigma \varphi$ in the meridional direction and this conclusion has been drawn from the comparison of $\sigma \varphi$ values obtained from the ANSYS model and the classical membrane theory of shells. The percentage different average between the two approaches is $2.2 \%$.

2- The present ANSYS12 model has produced the same level of accuracy in computing the membrane stresses in the hoop direction $\sigma \theta$ for the whole range of the angle $\phi$ the percentage different average for $\sigma \theta$ values between the ANSYS model and the classical membrane theory of shells is $3.3 \%$.

3- Regarding the ribbed monolithic reinforce concrete dome under the effect downward point load at crown the present finite element model has shown high efficiency in describing the variation of membrane normal stresses in the three orthogonal direction $\mathrm{x}, \mathrm{y}$ and $z$ with the meridional angle $\phi$. The numerical analysis result followed strictly the behavior given by the elementary membrane shell analysis. In the variation of membrane normal stresses in the $x, y$ and $z$ direction, the $\sigma X$ and $\sigma Z$ increased from compression at crown to max. tension at the dome base.
4- In the case of ribbed monolithic concrete dome, the analysis by ANSYS12 model has shown the monotontoic increases of $\sigma X$ and $\sigma z$ values from the dome crown, where this two stresses at angle $\phi$ values of $30^{\circ}$ and $46^{\circ}$, respectively given max. tensile stresses value after with those stress decreases gradually till they vanish at the dome base.

5- For the same dome case above (ribbed monolithic type) the normal stresses oy, varies slightly from crown $(\phi=0)$ to $\phi=31^{\circ}$ after which this stresses vanish continually along the meridional path till the dome base $\left(\phi=90^{\circ}\right)$. Variation of vertical displacement along the meridional path toward the dome base has similar trend of oy. This behavior consist of the primary inspection of the elementary membrane theory of shells.

6- Variation of the three principal normal stresses $\sigma x$, $\sigma y$ and $\sigma z$, the vertical displacement along the meridional path from apex of ribbed composite concrete dome of partial interaction at interface (case(3) of the present analysis ) to its base, predicted by the present finite element model, has almost the same trends as those of case(2) dome (ribbed monolithic concrete dome) but with larger variations. This behavior is quite realistic as it reflects the effect of the partial interaction at interfaces. 
7- The present finite element analysis shown that the increasing of dome diameter from $100-150 \mathrm{~m}$ causes increasing in all ultimate load capacity of the two types with $54 \%$ and $17.6 \%$ for dome cases one and three respectively and increasing of dome diameter from $70-100 \mathrm{~m}$ causes increasing in all ultimate load capacity with $16.9 \%$ for dome case one. The decreasing of dome diameter from $100-50 \mathrm{~m}$ causes decreasing in all ultimate load capacity of the two types with $45.6 \%$ and $12.9 \%$ for dome cases one and three respectively and decreasing of dome diameter from 70-50 $\mathrm{m}$ causes decreasing in all ultimate load capacity with $44.4 \%$ for dome case one.

8- Increasing of dome cover from $70-100 \mathrm{~mm}$, cause to increase in all ultimate load capacity of the three types with $17.8 \%$, $17.9 \%$ and $13.9 \%$ respectively. The decreasing of dome cover from $70-50 \mathrm{~mm}$ cause to decrease in all ultimate load of the three types with $6.5 \%, 11.7 \%$ and $13.5 \%$ respectively.

9- Increasing of concrete compressive strength $f^{\prime} c$ from $30 \mathrm{MPa}$ to $35 \mathrm{MPa}$, cause to increase in all ultimate load capacity with $10.7 \%, 11 \%$ and $8 \%$ for dome cases one, two and three respectively. The decreasing of concrete compressive strength $f^{\prime} c$ from $30 \mathrm{MPa}$ to $25 \mathrm{MPa}$, cause to decrease in all ultimate load capacity with $9 \%, 11 \%$ and $6 \%$ for dome cases one, two and three respectively.

10- Increasing the numbers of axsymmtric meridional ribs from two to four in the dome of cases two and three, causes increasing in all ultimate load capacity with $25.5 \%$ and $18 \%$ for dome cases two and three respectively. The removal of the two original meridional ribs in the dome of cases two and three, cause to decrease in all ultimate load capacity with $24.4 \%$ and $17.8 \%$.
11- The deceasing of $30 \%, 60 \%$ and $100 \%$ of steel ratio (crossing the joint) caused a decreasing of $15.9 \%, 29 \%$ and $38 \%$ respectively in the ultimate load capacity.

\section{REFERENCES}

[1] Chandrashekhra K. "Analysis of Thin Concrete Shells", $2^{\text {nd }}$ ed., new age international publishers, India, 1995.

[2] Tony R. "Engineering a new Architecture", QuebecorEusey, Leominster, Massachusetts, USA, 1996.

[3] Chen W.F. "Experiments on Axially Loaded Concrete Shells", Journal of the Structural Division, Proceeding of the American Society of Civil Engineers, Vol.105, No.ST8 , August, 1979.

[4] Zweilfel CH. "Harvard Design Magazine", Harvard College,1997.

[5] Manasrah A. " Ferrocement Segmented Shell Structures", M.Sc. Thesis, University of Technology, Building and Construction Department. Baghdad-Iraq, September, 1993.

[6] Ford E. "The Theory and Practice of Impermanence", Report from website, "Harvard Design magazine", number (3), Harvard college, 2001.

[7] Jackson Mississippi Report " The Finding of Structural Evaluation of the 5 meter Diameter Dome", 2002.

[8] Chatterjee B. " Theory and Design of Concrete shells" , $3^{\text {rd }}$ ed., Oxford and IBH Publishing, New Delhi, 1998.

[9] Theory, Analysis and Element Manuals, ANSYS help V.12, 2009.

[10] Hani Aziz Ameen "The Effect of Coupled - Field on the Vibration Characteristics and Stresses of Turbomachinery System", European Journal of Scientific Research ISSN 1450-216X Vol.41 No.4, pp.606-626, 2010.

[11] David P. Billington "Thin Shell Concrete Structure", $2^{\text {nd }}$ edition, McGrawHill Publishing Co., 1990. 